Article

Subscriber access provided by King Abdullah University of Science and Technology Library

\title{
Impact of polymer sidechain modification on OPV morphology and performance
}

Victoria Savikhin, Maxime Babics, Marios Neophytou, Shengjian Liu, Stefan D. Oosterhout, Hongping Yan, Xiaodan Gu, Pierre M. Beaujuge, and Michael F. Toney

Chem. Mater., Just Accepted Manuscript • DOI: 10.1021/acs.chemmater.8b03455 • Publication Date (Web): 19 Oct 2018

Downloaded from http://pubs.acs.org on October 24, 2018

\section{Just Accepted}

"Just Accepted" manuscripts have been peer-reviewed and accepted for publication. They are posted online prior to technical editing, formatting for publication and author proofing. The American Chemical Society provides "Just Accepted" as a service to the research community to expedite the dissemination of scientific material as soon as possible after acceptance. "Just Accepted" manuscripts appear in full in PDF format accompanied by an HTML abstract. "Just Accepted" manuscripts have been fully peer reviewed, but should not be considered the official version of record. They are citable by the Digital Object Identifier (DOI®). "Just Accepted" is an optional service offered to authors. Therefore, the "Just Accepted" Web site may not include all articles that will be published in the journal. After a manuscript is technically edited and formatted, it will be removed from the "Just Accepted" Web site and published as an ASAP article. Note that technical editing may introduce minor changes to the manuscript text and/or graphics which could affect content, and all legal disclaimers and ethical guidelines that apply to the journal pertain. ACS cannot be held responsible for errors or consequences arising from the use of information contained in these "Just Accepted" manuscripts. 


\section{INTRODUCTION}

In the search for sustainable, economical energy sources, organic photovoltaic (OPV) devices have emerged as a less costly alternative to traditional inorganic photovoltaics that may be useful in alternative applications such as building-integrated photovoltaics. Through careful manipulations of material properties and processing steps, OPV devices now regularly achieve efficiencies near 8-10\%, with a record efficiency of over $14 \%(1)$. Promises of lightweight materials, cheap fabrication, and flexible form factor drive considerable interest in making OPV's marketable. Yet, there is still a lack of in-depth understanding of the design rules governing performance, partly due to the difficulty of controlling and measuring the nanoscale morphology of these soft materials.

In a standard OPV device, a conjugated polymer or small molecule electron donor is mixed in solution with a fullerene derivative electron acceptor. When deposited onto a substrate and dried, the mixture partially phase separates into a bulk heterojunction (BHJ) structure containing acceptor- and donor-enriched phases. Light is absorbed creating excitons (bound electron-hole pairs) which either recombine, causing energy losses, or are separated into charge carriers at a material interface, generating current. Whether free carriers are generated and extracted depends on a few factors in the $\mathrm{BHJ}$ morphology. First, an exciton generated in a donor or acceptor region must reach an exciton-splitting interface before geminate recombination occurs: thus, donor- and acceptor- rich domains must not be much larger than the exciton diffusion length of $\sim 10 \mathrm{~nm}$. Second, excitons must be split into free charges efficiently at the donor-acceptor interface. Finally, free carriers generated through exciton splitting must have access to an uninterrupted, highmobility pathway to their respective electrodes. Free carriers that encounter a trap state, such as a donor molecule within an acceptor domain or vice versa, may be 
lost via non-geminate recombination. Nanoscale morphology profoundly affects each of these factors.

In addition to donor- and acceptor-rich domains functioning as hole- and electron-transporting pathways respectively, some BHJs contain a "mixed phase" in which donor and acceptor molecules are intermingled. The existence of a mixed phase may be beneficial to device function as it can create an energetic driving force pushing electrons and holes toward acceptor- and donor-rich domains respectively (2). At the same time, demixing of a previously mixed phase has been shown to be a leading cause for burn-in degradation in one polymer:fullerene system (3). However, the importance of the mixed phase is currently unknown, as there are few measurements of degree of mixing in the literature. It has been shown that mixed phase is not present in at least one efficient small molecule system, indicating that it may be unnecessary for good performance (4) (5).

In this work, we will focus on the control and influence of polymer orientation, intermolecular packing, crystallinity, and mixed phase. In particular, we look at a high-performing polymer backbone, poly(benzo[1,2-b:4,5$\mathrm{b}^{\prime}$ ]dithiophene-alt-thieno[3,4-c]pyrrole-4,6-dione)

(PBDTTPD), with four different sidechain combinations, from the set: 2-ethylhexyl (2EH), octyl (C8), and tetradecyl $\left(\mathrm{C}_{14}\right)$. We study both neat polymer films and BHJ's with $[6,6]$-Phenyl-C 71 -butyric acid methyl ester $\left(\mathrm{PC}_{71} \mathrm{BM}\right)$. The chemical structures of these materials are shown in Figure 1a). The polymer backbone consists of an electronwithdrawing (TPD) and electron-donating (BDT) moiety, which serves to decrease the polymer bandgap, making it better-tuned to visible light absorption (6) (7). This backbone has been studied in several publications (8) (9) (10) (11) (12) (13), including one study on its use in efficient homo-tandem devices (14).

Polymer sidechains are necessary to promote the dissolution of conjugated polymers in solvents for solution processing, but they are insulating and electronically inactive. Despite this, sidechain modification has been shown to significantly change OPV device parameters (short-circuit current, open-circuit voltage, etc.), primarily through morphological modification and changes to how the polymer interacts with fullerene derivatives (15), although changes to energy levels have also been observed (16) (17) (18) (19) (20) (21). In (16), (18), (19), and (20) an increase in the number of carbon atoms contained in the sidechains (hereafter referred to as $\mathrm{N}_{\mathrm{C}}$ ) mostly led to lowerlying HOMO levels and higher $\mathrm{V}_{\mathrm{OC}}$, though ultimately the highest $\mathrm{V}_{\mathrm{OC}}$ in (16) belonged to the polymer with the most linear sidechain and second-highest $\mathrm{N}_{\mathrm{C}}$. In (17), the smaller $\mathrm{N}_{\mathrm{C}}$ but more branched material had lower HOMO and higher $\mathrm{V}_{\mathrm{OC}}$. In (21), energy levels and $\mathrm{V}_{\mathrm{OC}}$ varied for a wide variety of sidechain combinations; it was difficult to extract general trends from this study because multiple variables were modified simultaneously, though in one case more branching led to higher $\mathrm{V}_{\mathrm{OC}}$.
For some polymers, more sidechain branching, increased $\mathrm{N}_{\mathrm{C}}$, or increased sidechain attachment density has been correlated with an increase in face-on orientation which may result in better out-of-plane charge transport (22) (23) (24) (25) (26). This may be due to the way that bulky sidechains hinder $\pi-\pi$ stacking through steric interactions, delaying the onset of and/or decreasing polymer crystallization (18) (22) (27). Meanwhile, linear sidechains have a lower steric hindrance than branched sidechains, resulting in higher backbone planarity, higher crystallinity (25), and stronger interaction with fullerene (28). Moving sidechain bulk farther away from the backbone also reduces steric interactions (29), increasing crystallinity (30) (31). In another work, relative lengths of adjacent sidechains are reported to have a larger effect on orientation than $\mathrm{N}_{\mathrm{C}}$ /branching, where more similar sidechain length correlates with more face-on material (32). Similarly, branched sidechains in which both branches are the same length create less torsion and higher crystallinity than equivalent structures with branches of different lengths (33). Among one small molecule with branched sidechains, the length of the sidechains significantly affects crystalline structure, phase separation, and device performance (34).

Previous work on PBDTTPD-backbone polymers specifically has shown that sidechains can change polymer orientation (8) (9) (10), packing distances (8) (9) (10) (11), crystallinity (8), mobility (11), degree of charge transfer state delocalization and dissociation efficiency (11), bimolecular recombination (10) (11), device parameters (9) (10) (11), and polymer-fullerene interactions (12). These previous studies have been very valuable in shedding light on sidechain influence in devices, but more research is needed to develop an understanding of sidechain impact and rules for effective sidechain design. Systematic variation of sidechain properties is needed, and changes to morphology must be thoroughly analyzed. In particular, the effect of sidechains on intermixing between polymer and fullerene has not been sufficiently explored, although one study suggests that $20-30 \%$ of the fullerene is mixed in PBDTTPD (2EH/C8): $\mathrm{PC}_{61} \mathrm{BM}(2)$ and another indicates that PBDTTPD $(2 \mathrm{EH} / \mathrm{C} 8)$ allows favorable $\mathrm{PC}_{61} \mathrm{BM}$ docking at the TPD moiety compared to other sidechain combinations (12).

Figure 1. a) Chemical structures of PBDTTPD, sidechains, and $\mathrm{PC}_{71} \mathrm{BM}$. b) Illustrations of the four sidechain combinations studied here, where squares represent a backbone unit and lines represent sidechains of varying branching and length. The color and marker shape for each combination is consistent throughout this work for ease of comparison: $(\mathbf{2 E H} / \mathbf{C} 8)=$ red triangle, $\quad(\mathbf{2 E H} / \mathbf{2 E H})=$ blue circle, $\left(\mathrm{C}_{14} / \mathbf{2 E H}\right)=$ black no marker, $\left(\mathrm{C}_{14} / \mathrm{C} 8\right)=$ green square .

Here, we will examine PBDTTPD conjugated polymers with four sidechain variations, shown in Figure $1 \mathrm{~b}$ ): (2EH/C8), (2EH/2EH), $\left(\mathrm{C}_{14} / \mathbf{2 E H}\right)$, and $\left(\mathrm{C}_{14} / \mathrm{C} 8\right)$. This set covers each combination of sidechains: $2 \mathrm{EH}$ versus $\mathrm{C}_{14}$ on 
$\mathbf{R}_{\mathbf{1}}$ and $2 \mathrm{EH}$ versus $\mathrm{C} 8$ on $\mathbf{R}_{\mathbf{2}}$. This allows us to isolate the effects from each sidechain substitution. We find that sidechains can modify all device performance parameters, domain sizes, polymer packing distances, polymer crystallinity, polymer orientation, and mixed phase. This study provides additional data points that will aid in arriving at design rules. The highest performing polymer, (2EH/C8), has negligible mixed phase, but achieves an average PCE of $8.06 \%$ with favorable domain sizes and orientation. Our in-depth analysis of domain formation in (2EH/C8) indicates that domain sizes may be controlled by self-assembling aggregates of 10-20 nm diameter.

\section{DEVICE PERFORMANCE}

Device parameters are given in Table 1 , and J-V curves are given in Figure Sia). Device stacks are PEDOT/active layer/Ca/Al. At least 5 devices of each type are averaged; more details can be found in the S.I.

Bulk heterojunction layers for three of the sidechains were about $100 \mathrm{~nm}$ thick with good uniformity, but the $\left(\mathbf{C}_{14} / \mathbf{C 8}\right)$ combination made films that were about $3 \mathrm{x}-5 \mathrm{x}$ thicker with poor uniformity (see S.I. and Figure $\mathrm{S}_{7}$ ). This was especially true for films with less than $50 \% \mathrm{PC}_{71} \mathrm{BM}$ that will be discussed in upcoming sections, which were significantly thicker toward the middle of the spin-cast sample versus the edges. We believe this is due to a higher solution viscosity, with solvent evaporation at the edges of the film occurring more quickly than the solution can spread. As the edges of the film dry, an increasingly thick bead of solution is left at the center of the sample. This is accompanied by a large surface roughness seen in profilometry, which is expected for inadequate solvent spreading (35). In previous literature, increase in surface roughness in the PBDTTPD system has been attributed to poor solubility (36), but this is unlikely given the bulky $\mathrm{C}_{14}$ sidechains. Instead, we suggest that this change is due to entanglement of the long $\mathrm{C}_{14}$ sidechains in a gel-like process, which is prevented in $\left(\mathbf{C}_{14} / \mathbf{2} \mathbf{E H}\right)$ by steric hindrance of the branched $\mathbf{R}_{\mathbf{2}}$ sidechain. This kind of gelation has been seen before in a polymer as a result of long sidechains with a branchpoint far removed from the backbone $\left(\mathrm{C}_{3} \mathrm{H}_{5}+\mathrm{C}_{8} \mathrm{H}_{17} / \mathrm{C}_{10} \mathrm{H}_{21}\right)$, while it was not present in its analog with a closer branch $\left(\mathrm{C}_{2} \mathrm{H}_{3}+\mathrm{C}_{12} \mathrm{H}_{25} / \mathrm{C}_{10} \mathrm{H}_{21}\right)$ due to steric hindrance (37). The significant difference in thickness must be considered when comparing $\left(\mathbf{C}_{14} / \mathbf{C 8}\right)$ to other sidechains. In particular, high thickness has been associated with dramatically decreased FF due to high recombination in many systems (2), though in some systems this effect has been small (38) (39). High thickness may also decrease degree of orientation of polymer backbones due to diminishing substrate effects. On the other hand, bulk characteristics such as domain sizes, polymer packing distances, degree of crystallinity, and amount of mixing with $\mathrm{PC}_{71} \mathrm{BM}$ should be mostly unaffected by the large thickness. It is important to analyze the bulk morphology of $\left(\mathbf{C}_{\mathbf{1 4}} / \mathbf{C 8}\right)$ despite its differences from the three other materials, as gelation is important in controlling self-assembly of BHJs (40) (41) (42) and may even be beneficial to film deposition (43).

The $(2 \mathbf{E H} / \mathbf{C} 8)$ blend is the highest performing blend with an average PCE of $8.06 \%$. The PCE most closely follows the $\mathrm{J}_{\mathrm{SC}}$ and the FF, which are both best for $(2 \mathrm{EH} / \mathrm{C} 8)$ and worst for $\left(\mathrm{C}_{14} / \mathbf{2 E H}\right)$. (2EH/2EH) and $\left(\mathbf{C}_{14} / \mathrm{C8}\right)$ have similar $\mathrm{J}_{\mathrm{SC}}, \mathrm{FF}$, and PCE values. $\mathrm{V}_{\mathrm{OC}}$ is highest in $(\mathbf{2 E H} / \mathbf{C 8})$ and $(2 \mathrm{EH} / \mathbf{2} \mathrm{EH})$, followed by $\left(\mathbf{C}_{14} / \mathbf{C 8}\right)$ and then $\left(\mathbf{C}_{14} / \mathbf{2 E H}\right)$. From this analysis we can conclude that substituting the $\mathbf{R}_{\mathbf{1}}$ sidechain from the compact $2 \mathrm{EH}$ to the bulkier $\mathrm{C}_{14}$ may impact $\mathrm{V}_{\mathrm{OC}}$, although this trend in $\mathrm{V}_{\mathrm{OC}}$ has not been found in the literature for these same materials (with some differences-see Table S2) (9) (12). Even though the mass fraction of insulating sidechain to semiconducting backbone increases from 0.48 to 0.58 when replacing (2EH) with $\left(\mathrm{C}_{14}\right)$ at $\mathbf{R}_{\mathbf{1}}$, this appears to not be a dominating factor in determining charge transport: in fact, $\left(\mathbf{C}_{14} / \mathbf{C 8}\right)$ has similar $\mathrm{J}_{\mathrm{SC}}$ and $\mathrm{FF}$ as $(\mathbf{2} \mathbf{E H} / \mathbf{2} \mathrm{EH})$, despite having more insulating material and a higher thickness.

Table 1. Device parameters for optimized devices made with PBDTTPD polymers.

\begin{tabular}{|l|l|l|l|l|l|}
\hline & $\begin{array}{l}\mathrm{J}_{\mathrm{SC}} \\
\left(\mathrm{mA} / \mathrm{cm}^{2}\right)\end{array}$ & $\begin{array}{l}\mathrm{V}_{\mathrm{OC}} \\
(\mathrm{V})\end{array}$ & $\begin{array}{l}\mathrm{FF} \\
(\%)\end{array}$ & $\begin{array}{l}\text { Avg. } \\
\mathrm{PCE} \\
(\%)\end{array}$ & $\begin{array}{l}\text { Max } \\
\mathrm{PCE} \\
(\%)\end{array}$ \\
\hline$(2 \mathrm{EH} / \mathrm{C} 8)$ & $\begin{array}{l}12.3 \\
\pm 0.1\end{array}$ & $\begin{array}{l}0.94 \\
\pm 0.01\end{array}$ & $\begin{array}{l}70.1 \\
\pm 0.3\end{array}$ & $\begin{array}{l}8.06 \\
\pm 0.07\end{array}$ & 8.14 \\
\hline$(2 \mathrm{EH} / 2 \mathrm{EH})$ & $\begin{array}{l}8.6 \\
\pm 0.1\end{array}$ & $\begin{array}{l}0.95 \\
\pm 0.01\end{array}$ & $\begin{array}{l}48.9 \\
\pm 0.7\end{array}$ & $\begin{array}{l}4.00 \\
\pm 0.07\end{array}$ & 4.09 \\
\hline$\left(\mathrm{C}_{14} / \mathrm{C} 8\right)$ & $\begin{array}{l}8.8 \\
\pm 0.2\end{array}$ & $\begin{array}{l}0.89 \\
\pm 0.01\end{array}$ & $\begin{array}{l}47.3 \\
\pm 0.6\end{array}$ & $\begin{array}{l}3.72 \\
\pm 0.08\end{array}$ & 3.81 \\
\hline$\left(\mathbf{C}_{14} / \mathbf{2 E H}\right)$ & $\begin{array}{l}6.9 \\
\pm 0.2\end{array}$ & $\begin{array}{l}0.83 \\
\pm 0.01\end{array}$ & $\begin{array}{l}34.6 \\
\pm 1.0\end{array}$ & $\begin{array}{l}1.98 \\
\pm 0.09\end{array}$ & 2.15 \\
\hline
\end{tabular}

Footnote: Devices are stacked PEDOT/active layer/Ca/Al. The active layer is comprised of polymer: $\mathrm{PC}_{71} \mathrm{BM}$ in a 1:1.5 ratio, spin cast from chlorobenzene with $5 \%$ chloronaphthalene additive. At least five devices are averaged for each measurement and values are reported with \pm standard deviation.

We compared our results to available literature on PBDTTPD-based devices, as shown in Table S2. Slight differences in parameters between our work and (9) may be due to differences in molecular weight; literature suggests that $M_{n}$ significantly impacts PBDTTPD-based devices (13). The molecular weight characterization of our polymers is given in Table S1. Larger differences between our work and (12) are likely due to their use of $\mathrm{PC}_{61} \mathrm{BM}$ instead of $\mathrm{PC}_{71} \mathrm{BM}$, but the trends between sidechains are roughly consistent with our results. More details can be found in the S.I and Table S2.

We also examined the device hole and electron mobility for the four materials, as described in the S.I. and Figure Sib). The measured mobility values differed significantly between devices, but unfortunately there was a large 
uncertainty in the results. This made it difficult to draw any conclusions regarding the effect of sidechains on mobility.

\section{COMPARISON OF DOMAIN SIZES BETWEEN SIDECHAINS}

We used Resonant Soft X-ray Scattering (RSoXS) measurements to compare the domain sizes in each material blend. RSoXS has been used to probe domain sizes in organic materials. This method provides bulk-averaged data on length scales from about 3 to $100 \mathrm{~nm}$ (44) and can complement AFM, which only measures the surface structure. Surface roughness does have a contribution to scattering, but carefully tuning the X-ray beam energy can increase the contribution of bulk scattering compared to surface scattering.

In RSoXS, changing the incident X-ray energy changes the contrast, which is a measure of how strongly a material scatters and is proportional to signal intensity (44). We used an incident energy of $284.2 \mathrm{eV}$, which typically results in the best contrast in PCBM-based OPV materials (45), and confirmed that contrast in our materials is approximately maximized at this energy as well (see S.I.; Figure $\mathrm{S}_{2}$ and Table $\mathrm{S}_{3}$ ). We further estimated polymer $/ \mathrm{PC}_{71} \mathrm{BM}$ and sample/vacuum contrast versus incident energy to ascertain that scattering from the bulk dominates over surface scattering in our measurement. This is done by measuring X-ray absorption (NEXAFS) of the neat materials to calculate the complex index of refraction. Details are given in the S.I. At $270 \mathrm{eV}$, material/vacuum contrast is considerably higher than polymer/fullerene contrast, so surface topography is expected to dominate the scattering pattern. Material/vacuum contrast increases by about 10x from 270 to $284.2 \mathrm{eV}$, while polymer/fullerene contrast increases by 200-400x (see Table S3). Thus, differences in RSoXS between 270 and $284.2 \mathrm{eV}$ are attributed to domain scattering.

RSoXS data was collected on a $2 \mathrm{D}$ detector, circularly integrated, and normalized by the beamstop photodiode reading (roughly equivalent to incident beam intensity $\mathrm{x}$ sample transmission). Data is shown in Figure 2 with arbitrary normalization for ease of comparison and in Figure $\mathrm{S}_{4}$ with this normalization. We also discuss possible anisotropy of the data in the S.I. and Figure S3 $_{3}$, though this does not change our overall conclusions. Small angle scattering in complex nanostructures is challenging to model, but strong peaks or shoulders in scattering curves indicate the presence of preferential domain sizes in the material, making a qualitative comparison of domain sizes possible. Scattering angle and domain size have an inverse relationship, such that shoulders at higher $Q$ indicate smaller domains.

At $270 e \mathrm{~V}$, intensity is mainly concentrated at low $\mathrm{Q}$ for all four materials, which is consistent with surface roughness. $(\mathbf{2} \mathbf{E H} / \mathbf{2} \mathbf{E H})$ and to a smaller extent $\left(\mathbf{C}_{14} / \mathbf{2} \mathbf{E H}\right)$ also exhibit weak scattering shoulders at about $0.011 \AA^{-1}$ consistent with their scattering patterns at $284.2 \mathrm{eV}$. A unified exponential/power-law fit (46) to the region $0.006<\mathrm{Q}<0.04 \AA^{-1}$, shown in Figure $\mathrm{S}_{5}$, gives a prefactor (related to scattering intensity) that increases by roughly 140x $\left(\mathbf{C}_{14} / \mathbf{2 E H}\right)$ and $180 \mathrm{ox}(2 \mathrm{EH} / \mathbf{2} \mathrm{EH})$ from $270 \mathrm{eV}$ to 284.2 $\mathrm{eV}$. Since material/vacuum scattering contrast is expected to increase by only 10x, both surface and bulk are likely contributing to this scattering shoulder, with domain structure templating the surface topography. A high degree of surface roughness has previously been associated with poor dissolution of PBDTTPD in casting solvents (36).

In Figure 2b), the RSoXS is largely featureless and so all blends have a large range of domain sizes. However, $(2 \mathbf{E H} / 2 \mathbf{E H})$ and $\left(\mathbf{C}_{14} / \mathbf{2 E H}\right)$ both exhibit shoulders near o.o11 $\AA^{-1}$, roughly correlating with domain sizes in the 30 $60 \mathrm{~nm}$ range. The exciton diffusion length is in the 5-20 $\mathrm{nm}$ range in organic materials (47), so it is likely that $(\mathbf{2 E H} / \mathbf{2 E H})$ and $\left(\mathbf{C}_{14} / \mathbf{2} \mathrm{EH}\right)$ encounter some recombination losses due to having domains of this size. (C14/C8) and (2EH/C8) do not have this o.o11 $\AA^{-1}$ shoulder but instead exhibit significant scattering shoulders in the high Q region near 0.03-0.06 $\AA^{-1}$, corresponding to the 10$20 \mathrm{~nm}$ domain sizes which are necessary for efficient exciton splitting. Behavior at $\mathrm{Q}<0.003 \AA^{-1}$ is strongly affected by surface roughness and cannot be used to make conclusions about domain structure. $\left(\mathbf{C}_{\mathbf{1 4}} / \mathbf{C 8}\right)$ exhibits the biggest increase in scattering at $\mathrm{Q}<0.003 \AA^{-1}$ which is consistent with its poor film uniformity.

Figure 2. RSoXS data from PBDTTPD:PC ${ }_{71} \mathrm{BM}$ (1:1.5) blend films at an incident energy of $284.2 \mathrm{eV}$. Detector intensity $\mathrm{I}(\mathrm{Q})$ is shown in a) while $I(Q) \cdot Q^{2}$ is plotted in $b$ ). For ease of comparison, data is arbitrarily vertically offset (multiplied by a scaling factor) here. Data normalized by the incident intensity and additional data can be found in Figure $\mathrm{S}_{4}-\mathrm{S}_{5}$.

It is clear that modifying sidechains can change the domain structure in BHJs. Similar RSoXS patterns are found for $\left(\mathrm{C}_{14} / \mathbf{2} \mathrm{EH}\right) \&(2 \mathrm{EH} / 2 \mathrm{EH})$ and for $\left(\mathrm{C}_{14} / \mathrm{C} 8\right)$ \& (2EH/C8); thus the $\mathbf{R}_{\mathbf{2}}$ sidechain on TPD is the main contributor to domain size differences in this system. The domain sizes present in each material blend shed some light on the differences in performance. Both $\left(\mathbf{C}_{14} / \mathbf{2 E H}\right) \&$ $(\mathbf{2} \mathbf{E H} / \mathbf{2} \mathbf{E H})$ lack the small domains necessary to promote good charge separation, while these are present in $\left(\mathrm{C}_{14} / \mathrm{C8}\right)$ \& (2EH/C8). Accordingly, both $\left(\mathrm{C}_{14} / \mathrm{C8}\right)$ and $(2 \mathrm{EH} / \mathrm{C8})$ have a $\sim 2 \mathrm{x}$ higher efficiency than their analogs with $\mathbf{R}_{2}=2 \mathrm{EH}$ caused by changes in $\mathrm{FF}$ and $\mathrm{J}_{\mathrm{sc}}$. On the other hand, the $2 x$ difference in efficiency between $\left(\mathbf{C}_{14} / \mathbf{C 8}\right)$ and $(\mathbf{2 E H} / \mathbf{C 8})$, and between $\left(\mathbf{C}_{14} / \mathbf{2 E H}\right)$ and $(2 \mathbf{E H} / \mathbf{2 E H})$, cannot be explained by domain size considerations on these length scales, though as noted in the previous section $\left(\mathbf{C 1}_{14} / \mathbf{C 8}\right)$ may suffer recombination losses due to large thickness. In the next sections, we examine other morphological characteristics in these systems to further explain differences in device performance.

POLYMER CRYSTALLINITY AND PACKING IN NEAT AND BLEND FILMS 
We used 2D Grazing Incidence Wide Angle X-ray Scattering (GIWAXS) to compare the crystal structures of polymers with different sidechains, as well as comparing the domain composition between these materials. GIWAXS gives a wealth of information on polymer morphology. From the locations of scattering peaks, we can estimate the packing distances and the orientation of the polymer backbone with respect to the substrate. The intensities of peaks give us information about the amount of crystalline material. Comparing the peak intensities for blends of different compositions can give information on the amount of mixed phase and the effect of mixing on polymer crystallinity. We will discuss each of these aspects in the following sections.

GIWAXS images for the four polymers in neat and optimized blend films are shown in Figure 3. Details of our robust analysis strategy are given in the S.I. and Table $\mathrm{S}_{4}$. The intermolecular packing distances, total peak scattering intensities (PSI), and orientations were measured and compared between the four types of sidechains. These results are summarized in Table $\mathrm{S}_{5}$, Figure 4, and Figure 5.

Figure 3. GIWAXS patterns for neat polymers (top) and optimized blends (6o\% $\mathrm{PC}_{71 \mathrm{BM}}$ ) (bottom) with four different sidechain configurations, as labeled.

Comparing crystallinity between disparate chemical structures is difficult. While sidechains are typically thought of as disordered in intermolecular regions between rigid backbones, they may still contribute to scattering intensity. Furthermore a change in stacking distance will change the scattering intensity. However, the total peak scattering intensity (PSI) can still be used as a rough measure of the relative degree of crystallinity (rDOC), especially if changes to scattering intensity are large.

For both neat and blend films, PSIs (see Table $\mathrm{S}_{5}$ ) follow the order: $(\mathbf{2 E H} / \mathrm{C8})>\left(\mathrm{C}_{14} / \mathbf{2 E H}\right)>\left(\mathrm{Cl}_{14} / \mathrm{C8}\right)>(\mathbf{2 E H} / \mathbf{2 E H})$. PSI increases by around $2 x$ from the neat to blend film for all sidechains; this will be discussed in depth in the "intermixing" section. The best-performing (2EH/C8) blend has a significantly higher scattering intensity than the other sidechain combinations, but the next highest PSI occurs in the worst-performing $\left(\mathbf{C}_{14} / \mathbf{2 E H}\right)$ blend. High crystallinity is thought to be beneficial for charge transport, as it minimizes energetic trap states caused by local environment fluctuation. While the best-performing system likely benefits from its higher crystallinity (leading to a high $\mathrm{FF}$ of $70 \%$ ), degree of crystallinity is not the dominant effect differentiating the three lower-performing systems.

Literature shows that the alkyl stacking distance depends primarily on the size of the sidechains (48) (23) (24) (34) (16) (17), and this is confirmed in our data. Changing $\mathbf{R}_{\mathbf{1}}$ from $2 \mathrm{EH}$ to $\mathrm{C}_{14}$, which adds a total of 12 carbon atoms to each monomer, increases the alkyl distance by 8.6-9.1 $\AA$ in neat and blend films (an increase of $40-50 \%$ ); see Figure $4 \mathrm{a}$ ). Furthermore, changing $\mathbf{R}_{\mathbf{2}}$ from 2EH to C8 increases alkyl distance by 1.6-2.2 $\AA$ (an increase of $6-12 \%)$ in neat and blend films, indicating that the linear sidechain extends farther in the alkyl direction than the branched sidechain.

The $\pi-\pi$ stacking distance, shown in Figure $4 \mathrm{~b}$ ), varies slightly with sidechain substitution in the neat films, and is inversely related to alkyl stacking distance. An increase in $\pi-\pi$ stacking distance may result from an increase in steric interference due to a sidechain preferring to extend in a direction normal to the backbone plane (the $\pi-\pi$ stacking direction). To understand these effects, we considered the results of molecular dynamics (MD) simulations on polymer strands in solution presented in (49). From this study, $\mathbf{R}_{1}=C_{14}$ preferentially extends in the alkyl direction, $\mathbf{R}_{\mathbf{2}}=\mathbf{2} \mathrm{EH}$ extends in the $\pi-\pi$ direction, and the other two sidechains have intermediate orientations. We find that changing $\mathbf{R}_{\mathbf{1}}$ from $\mathrm{C}_{14}$ to $2 \mathrm{EH}$ increases $\pi-\pi$ stacking distance in the neat film by 0.05 or $0.22 \AA$ ( 1 or $6 \%$ ), depending on the set of materials compared. Changing $\mathbf{R}_{\mathbf{2}}$ from $\mathrm{C} 8$ to $2 \mathrm{EH}$ increases $\pi-\pi$ stacking distance by 0.02 or $0.19 \AA$ (o.6 or $5 \%$ ). These results suggest that $\mathbf{R}_{\mathbf{1}}=\mathbf{2} E H$ and $\mathbf{R}_{\mathbf{2}}=\mathbf{2} E H$ interfere with the $\pi-\pi$ stacking more than $\mathbf{R}_{\mathbf{1}}=\mathrm{C}_{14}$ and $\mathbf{R}_{\mathbf{2}}=\mathrm{C} 8$, which is approximately consistent with the MD result. In other words, branched sidechains lead to larger $\pi-\pi$ stacking distances than linear sidechains in this set, even when the linear sidechain is significantly longer (more carbon atoms) than the branched sidechain.

In general, alkyl packing distances do not change significantly when polymers are blended with $\mathrm{PC}_{71} \mathrm{BM}$. Thus, we do not see dramatic increases in alkyl stacking distance that is associated with the formation of an intercalated polymer/fullerene co-crystal (50) (51). Other studies with similar polymers have observed slight contraction (52) or expansion (53) in stacking distances with fullerene blending. This effect sometimes depends on processing parameters (54) and is not always consistent between studies (53) (55). This effect is interesting to explore as it may imply changes in density, and high density has been related to a decrease in photo-oxidation (56). Nevertheless, in our work, changes in stacking distances are negligible in the in-plane direction, and slight changes in the out-of-plane direction can be attributed to X-ray refraction (57).

Figure 4. a) Comparison of alkyl stacking distances of neat and blend films; neat films are shown in a darker color. b) Comparison of $\pi-\pi$ stacking distances.

\section{POLYMER ORIENTATION IN NEAT AND BLEND} FILMS

The orientation of the polymer backbone with respect to the substrate is of interest because the current model of 
conjugated backbones suggests that more face-on materials will have better charge transport in the out-ofplane direction, leading to better $J_{s c}$ and FF. The crystallographic alkyl and $\pi-\pi$ stacking directions are sometimes used to estimate the backbone orientation (face-on versus edge-on). This approach assumes that the backbone is not tilted in the unit cell, i.e., the structure does not have a slip-stacked or herringbone motif, as described in (58) (59) (6o), and the backbone is not twisted. There is some evidence that positive and negative regions in an electrostatic potential (ESP) map of a polymer can be predictive of slip-stacking, as oppositelycharged regions are attracted to each other; further, alkyl sidechains do not greatly influence the ESP (58). Oppositely charged regions are present in the ESP map of the PBDTTPD(2EH/C8) polymer, indicating that slipping cannot be ruled out in this material (61). On the other hand, good planarity is expected (61).

Noting this possibility of slip-stacking, we compare the orientation of the alkyl and $\pi-\pi$ stacking peaks in neat and blend materials in Figure 5. The pole figures (corrected intensity vs polar angle) are plotted in Figure 5a,b,d,e). The alkyl and $\pi-\pi$ stacking directions are approximately orthogonal to each other such that the (alkyl peak direction $) \approx 90^{\circ}-(\pi-\pi$ peak direction $)$. For ease of discussion, we refer to the arrangement with an out-ofplane (OOP) alkyl and in-plane (IP) $\pi-\pi$ stacking peak as nominally "edge-on," and the opposite arrangement as nominally "face-on", although this refers only to the crystallographic (repeat) directions and not necessarily the backbone orientation. We also present an average peak orientation of the unit cell in Figure $5 \mathrm{c}, \mathrm{f}$ ) which allows us to compare the orientation of the polymers with a single parameter. Unless otherwise noted, the average orientation of the alkyl peak is used. An average alkyl peak orientation of $90^{\circ}$ is approximately edge-on while $0^{\circ}$ is approximately face-on. More details on the calculation of average orientation are given in the S.I.

Among neat materials, (2EH/C8) forms the most faceon orientation with an average alkyl orientation of $18^{\circ}$, while the other neat films have orientations near $45^{\circ}$ (isotropic, equal parts edge- and face-on, or tilted). Among optimized blends, $(\mathbf{2 E H} / \mathbf{C 8})$ is also the most face-on material $\left(26^{\circ}\right)$, followed by $\left(\mathbf{C}_{14} / \mathbf{C 8}\right)\left(44^{\circ}\right),(\mathbf{2 E H} / \mathbf{2 E H})$ $\left(50^{\circ}\right)$, and $\left(\mathbf{C}_{\mathbf{1 4}} / \mathbf{2} \mathbf{E H}\right)\left(65^{\circ}\right)$. Our results are consistent with the expectation that face-on orientation is beneficial for devices, since the trend in orientation correlates well with the $\mathrm{J}_{\mathrm{SC}}$ and FF measured in the devices. The correlation between face-on orientation and good performance is also consistent with results found in previous work (8) (9) (10). Substrate effects are weaker for $\left(\mathbf{C}_{14} / \mathbf{C 8}\right)$ due to its large thickness which may contribute to its near-isotropic orientation (near $45^{\circ}$ ), so we do not further discuss the orientation of $\left(\mathbf{C}_{\mathbf{1 4}} / \mathbf{C 8}\right)$ films.

Figure 5. a,b,d,e) Pole figures with $\sin (\chi)$ correction, where o and $180^{\circ}$ are in-plane and $90^{\circ}$ is out-of-plane polar angle. a,b) Alkyl peak; d,e) $\pi-\pi$ stacking peak; a,d) Neat films; b,e) blend films with $60 \% \mathrm{PC}_{71} \mathrm{BM}$, corresponding to devices. The $\pi-\pi$ stacking peak of $(\mathbf{2} \mathbf{E H} / \mathbf{2 E H})$ was difficult to isolate from background due to a large peak width, so it has been omitted. c,f) Average peak orientation versus $\mathrm{PC}_{71} \mathrm{BM}$ content for four sidechains, calculated from c) alkyl peak and f) $\pi-\pi$ stacking peak.

As discussed in the introduction, literature shows that larger and/or more branched sidechains result in more face-on behavior. From this we expect that changing $\mathbf{R}_{\mathbf{2}}$ from $\mathrm{C} 8$ to $2 \mathrm{EH}$ should make the film more face-on. Our results are not consistent with this and if anything show the opposite trend: $(\mathbf{2} \mathbf{E H} / \mathbf{C 8})$ is significantly more face-on than its analog $(\mathbf{2 E H} / \mathbf{2 E H})$ in both neat and blend films. Changing $\mathbf{R}_{\mathbf{1}}$ from $2 \mathrm{EH}$ to $\mathrm{C}_{14}$ makes the sidechain less branched but larger (more carbon atoms), so no prediction can be made regarding its effect. We observe that the average orientation is more face-on for $(\mathbf{2} \mathbf{E H} / \mathbf{2 E H})$ than $\left(\mathbf{C}_{14} / \mathbf{2 E H}\right)$ for neat and blend films.

Blending (2EH/C8), (2EH/2EH), and (C14/2EH) with $\mathrm{PC}_{71} \mathrm{BM}$ progressively makes the orientation more edge-on. This may be related to the decrease in polymer concentration in casting solution. We will discuss this effect in more detail in the "Discussion" section.

\section{INTERMIXING OF POLYMER AND FULLERENE}

The presence and function of finely mixed regions of polymer and fullerene have attracted considerable attention in recent literature. In this section, we explore the degree of intimate mixing between PBDTTPD and $\mathrm{PC}_{71} \mathrm{BM}$ to understand what effect sidechains have on miscibility. We also examine the effect $\mathrm{PC}_{71} \mathrm{BM}$ has on
PBDTTPD crystallization. To track the interactions between polymer and fullerene, we measured a series of blend films with varying concentrations of fullerene and extracted the relative phase fraction of pure polymer, pure fullerene and mixed phase. This technique has been demonstrated in previous works (4) (62), although here we use an advanced peak fitting routine described in the S.I. and Figure S8-Figure S14 rather than a simple linear combination to account for changes in peak position, width, and scattering from amorphous polymer. Each observable scattering peak can be assigned to either polymer or fullerene, based on results from the neat materials' scattering patterns. No new scattering peaks are observed in blend films in this work, which means that no crystallized mixed phase structure is present.

$\mathrm{PC}_{71} \mathrm{BM}$ molecules can either be aggregated (scattering) or molecularly dispersed in a mixed phase (nonscattering). In blends that don't have a mixed phase, all the $\mathrm{PC}_{71} \mathrm{BM}$ molecules will be aggregated and the $\mathrm{PC}_{71} \mathrm{BM}$ scattering intensity will be linearly proportional to the amount of $\mathrm{PC}_{71} \mathrm{BM}$ present in the film. On the other hand, molecular mixing will inhibit $\mathrm{PC}_{71} \mathrm{BM}$ scattering, and the $\mathrm{PC}_{71} \mathrm{BM}$ scattering peak intensity will fall below this linear relationship. The difference between the measured $\mathrm{PC}_{71} \mathrm{BM}$ scattering intensity and the expected no-mixed-phase 
intensity gives a measure of the fraction of $\mathrm{PC}_{71} \mathrm{BM}$ residing in a mixed phase. This concept is demonstrated in (4) (2) (5).

Results of the blend series measurements are shown in Figure 6 . The $\mathrm{PC}_{71} \mathrm{BM}$ peak intensity increases linearly with $\mathrm{PC}_{71} \mathrm{BM}$ concentration in $(\mathbf{2} \mathrm{EH} / \mathbf{C 8})$ indicating negligible mixed phase and nearly linearly in $(2 \mathbf{E H} / \mathbf{2 E H})$, but dips significantly below a linear relationship in $\left(\mathrm{C}_{14} / \mathbf{2} \mathrm{EH}\right)$ and $\left(\mathbf{C}_{14} / \mathbf{C 8}\right)$. Interestingly, the peak intensity is nonzero at low fullerene loadings, suggesting that the total amount of fullerene that is in a mixed phase depends on the fullerene concentration. This is unexpected because conventional phase diagrams suggest that all $\mathrm{PC}_{71} \mathrm{BM}$ should be in a mixed phase up to the miscibility limit, while all $\mathrm{PC}_{71} \mathrm{BM}$ above this limit should be unmixed (63) (64). This model has been used to fit the data in previous work, with the fraction of $\mathrm{PC}_{71} \mathrm{BM}$ in mixed phase determined by the concentration at which scattering intensity begins to grow (65) (2). Our data does not follow this shape, possibly because of rapid drying leading to a metastable state. Therefore we estimate the amount of intermixed $\mathrm{PC}_{71} \mathrm{BM}$ in devices $\left(60 \% \mathrm{PC}_{71} \mathrm{BM}\right)$ by fitting the data to a two-part line approximation and using the following relation:

Fraction mixed $=1-$ fraction aggregated $=1-\frac{F_{60 \%}}{0.6 \cdot F_{100 \%}}$

Where $\mathrm{F}_{60 \%}$ is the $\mathrm{PC}_{71} \mathrm{BM}$ peak scattering intensity of the optimized blend and $\mathrm{F}_{100 \%}$ is the scattering intensity of the neat $\mathrm{PC}_{71} \mathrm{BM}$. The fraction of $\mathrm{PC}_{71} \mathrm{BM}$ in a mixed phase is given in Table 2 . The two materials with $R_{1}=C_{14}$ have a large amount of mixed phase while the best performing (2EH/C8) blend has negligible mixed phase. The lack of mixed phase in $(\mathbf{2 E H} / \mathbf{C 8})$ may be related to its high degree of crystallinity, which is discussed as a contributing factor to a lack of mixed phase in the literature (4).

The trend in mixed phase is opposite to what molecular dynamics simulations have predicted previously for PBDTTPD:PC ${ }_{61} \mathrm{BM}$. Here, the number of branched sidechains was shown to correlate with amount of mixing, predicting that the amount of mixing should increase in the order $\quad\left(\mathbf{C}_{14} / \mathbf{C 8}\right)<\left(\mathbf{C}_{14} / \mathbf{2} \mathbf{E H}\right)<(\mathbf{2} \mathbf{E H} / \mathbf{C 8}) \quad(49)$. Simulations also predict that the orientation and position of $\mathrm{PC}_{61} \mathrm{BM}$ relative to the backbone changes significantly with sidechain substitution, and this may have an impact on the amount of mixed phase, though further analysis is outside the scope of this work (66). Notably, these studies analyze the relationship with $\mathrm{PC}_{61} \mathrm{BM}$ rather than $\mathrm{PC}_{71} \mathrm{BM}$, which may account for differences.

Next, we used the polymer scattering intensity to examine the effect that $\mathrm{PC}_{71} \mathrm{BM}$ has on polymer crystallization. In BHJs, polymers can exist in three phases: crystalline (scattering), amorphous (non-scattering), or intimately mixed (non-scattering). In a blend film, the degree of crystallinity of a polymer as a function of the amount of polymer may be higher or lower than in the neat film: higher, if the presence of $\mathrm{PC}_{71} \mathrm{BM}$ encourages polymer crystallization; lower, if $\mathrm{PC}_{71} \mathrm{BM}$ disrupts crystallization, either through intermixing or by changing the drying dynamics. In all four polymers, we observe some enhancement in alkyl peak intensities as $\mathrm{PC}_{71} \mathrm{BM}$ is added, shown in Figure 6. We use a quadratic function to smooth the data and estimate the amount of enhancement with the following relation:

$$
\% \text { Enhancement }=\frac{P_{60 \%}}{0.4 \cdot P_{0 \%}}
$$

Where $\mathrm{P}_{60 \%}$ is the polymer peak scattering intensity of the optimized blend with $60 \% \mathrm{PC}_{71} \mathrm{BM}$ and $\mathrm{P}_{0} \%$ is the scattering intensity of the neat polymer. From this we observe that the polymer is around twice as crystalline in the blend material as in the neat (1.7x to $2.5 \mathrm{x}$, see Table 2 ), despite the presence of a mixed phase in three of the materials. This result differs from that of some small molecules, where the degree of crystallinity was unchanged with fullerene content $<30 \%$ and was suppressed with higher fullerene content (4) (5). Other work has also suggested a decrease or lack of change in the degree of crystallinity of the polymers $\mathrm{PTB}_{7}$ (67), $\mathrm{P}_{3} \mathrm{HT}$ (68), and (2EH/C8) (with $\left.\mathrm{PC}_{61} \mathrm{BM}\right)(2)$ when blended with fullerene. On the other hand, at least one other polymer system (PIPCP:PC ${ }_{61} \mathrm{BM}$ ) experiences no mixed phase and a significant increase in order as fullerene is added, similar to our result (69). Another polymer:fullerene system $\left(\mathrm{P}\left(\mathrm{T}_{3}-\mathrm{TPD}\right): \mathrm{PC}_{71} \mathrm{BM}\right)$ has higher polymer crystallinity in the blend than the neat material when cast with a solvent additive, but the opposite is true when it is cast without the solvent additive $(70)$.

Figure 6. PSI from peak fitting as a function of $\mathrm{PC}_{71} \mathrm{BM}$ content, used to calculate the $\mathrm{PC}_{71} \mathrm{BM}$-induced enhancement of polymer crystallinity and the amount of mixed phase. Symbols show data and solid lines are smoothing functions used to calculate crystallinity enhancement and amount of mixed phase in Table 2. a-d) show the polymer alkyl peak intensity smoothed with a quadratic function, normalized by the value of the neat polymer film; e-h) show the $\mathrm{PC}_{71} \mathrm{BM}$ peak intensity smoothed with a twopart line, normalized by the value of the neat $\mathrm{PC}_{71} \mathrm{BM}$. Data is given for a,e) $\left.\left.(\mathbf{2} \mathbf{E H} / \mathbf{C 8}) ; \mathrm{b}, \mathrm{f}\right)(2 \mathbf{E H} / \mathbf{2} \mathbf{E H}) ; \mathrm{c}, \mathrm{g}\right)\left(\mathbf{C}_{\mathbf{1 4}} / \mathbf{C 8}\right)$; d,h $\left(\mathbf{C}_{14} / \mathbf{2} \mathbf{E H}\right)$.The large variance in $\left(\mathbf{C}_{14} / \mathbf{C 8}\right)(\mathrm{c})$ is due to thickness uncertainty arising from film roughness. 
Table 2. Mixed phase and polymer crystallinity in the BHJ device.

\begin{tabular}{|l|l|l|l|l|}
\hline & $\begin{array}{l}(2 \mathrm{EH} / \\
\mathrm{C} 8)\end{array}$ & $\begin{array}{l}(2 \mathrm{EH} / \\
2 \mathrm{EH})\end{array}$ & $\begin{array}{l}\left(\mathrm{C}_{14} /\right. \\
\mathrm{C} 8)\end{array}$ & $\begin{array}{l}\left(\mathrm{C}_{14} /\right. \\
\mathbf{2 E H})\end{array}$ \\
\hline $\begin{array}{l}\text { \% of PC71BM in } \\
\text { mixed phase }\end{array}$ & $\begin{array}{l}2 \\
\text { (negli } \\
\text { gible) }\end{array}$ & 11 & 39 & 30 \\
\hline $\begin{array}{l}\text { Inflection point } \\
\text { (\% PC71BM) }\end{array}$ & 20 & 27 & 47 & 42 \\
\hline $\begin{array}{l}\text { Enhancement } \\
\text { in crystallinity }\end{array}$ & 1.7 & 2.1 & 2.5 & 1.9 \\
\hline
\end{tabular}

Footnote: Showing amounts for the blend ratio used in devices, 1:1.5 polymer: $\mathrm{PC}_{71} \mathrm{BM}\left(60 \% \mathrm{PC}_{71} \mathrm{BM}\right)$. Amount of $\mathrm{PC}_{71} \mathrm{BM}$ in mixed phase is calculated by smoothing the data with a two-part line; crystallinity enhancement is calculated by smoothing data with a quadratic function, as shown in Figure 6.

In general, these results show that the degree of mixing with $\mathrm{PC}_{71} \mathrm{BM}$ is strongly affected by the sidechain selection, with larger sidechains resulting in more mixing. Notably, the $(2 \mathbf{E H} / \mathbf{C 8})$ system has high efficiency $(8.1 \%)$ and high $\mathrm{J}_{\mathrm{SC}}$ without a mixed phase. Furthermore, the presence of $\mathrm{PC}_{71} \mathrm{BM}$ enhances the degree of crystallinity by around $2 \mathrm{X}$ in all four polymers even when mixed phase is observed.

\section{DOMAIN FORMATION IN (2EH/C8): $\mathrm{PC}_{71} \mathrm{BM}$}

In this section, we examine the highest performing (2EH/C8) polymer in greater detail. From the high degree of crystallinity and negligible mixing shown in our work, and well-ordered cross-chain structure seen in high resolution transmission electron microscopy (HR-TEM) (71), it is clear that this polymer is strongly aggregating. This is also consistent with the literature (72) (28). Why then do the domain sizes in the optimized blend remain small? We collected RSoXS from different blend ratios of polymer: $\mathrm{PC}_{71} \mathrm{BM}$ to further understand the domain formation in this system. The results are shown in Figure 7a) with arbitrary scaling and in Figure S6 with beam intensity and thickness normalization. From the previous section, negligible mixed phase exists in the $(\mathbf{2 E H} / \mathbf{C 8})$ system, so the following analysis assumes a two-phase system.

As expected, there is negligible scattering from the neat polymer film, and scattering from neat $\mathrm{PC}_{71} \mathrm{BM}$ is concentrated at low $\mathrm{Q}$, corresponding to surface roughness. RSoXS intensity is maximized at $\mathrm{PC}_{71} \mathrm{BM}$ contents between 40 and $60 \%$. Interestingly, the shape of the scattering pattern beyond the surface roughness region (for $\mathrm{Q}>0.002 \AA^{-1}$ ) is fairly unchanged with fullerene content between 30 and $60 \%$. This is especially evident in the appropriately normalized plot in Figure S6. There is a shoulder at $Q>0.03 \AA^{-1}$ and an increase in scattering intensity near $Q \approx 0.003 \AA^{-1}$ (marked by dashed boxes in
Figure 7a), indicating a two-length-scale structure. The $40 \%$ film appears to have less concavity in the small $Q$ region which we attribute to overlap from scattering from a higher surface roughness from our film transfer procedure-notably, the overall intensity in this region remains comparable to the 30 and 50\% films. The high Q shoulder, which indicates small domains in the $10-20 \mathrm{~nm}$ range, emerges with as much as $90 \% \mathrm{PC}_{71} \mathrm{BM}$ and remains in a similar $\mathrm{Q}$ position as $\mathrm{PC}_{71} \mathrm{BM}$ decreases to $20 \%$. Because the $90 \%$ film consists of small amounts of polymer within a fullerene matrix, it is likely that these small domains are comprised of polymer. This constant length scale points to the polymer self-assembling into $10-20 \mathrm{~nm}$ aggregates which remain distinct even as polymer concentration becomes large.

Scattering at larger length scales $\left(\mathrm{Q} \approx 0.002-0.004 \AA^{-1}\right)$ becomes prominent with as much as $80 \% \mathrm{PC}_{71} \mathrm{BM}$. In this sample, the large length scale peak is broad, indicating a large distribution of domain sizes. Similarly to the $90 \%$ film, at $80 \%$ small polymer aggregates are dispersed between large regions of fullerene. While there is no fullerene structure in the $90 \%$ film, the $80 \%$ film contains enough polymer to start breaking up the fullerene matrix into large domains. Thus, fullerene domains likely make up the large length scale peak. With $40-70 \% \mathrm{PC}_{71} \mathrm{BM}$, the weak large length scale peak becomes more distinct and moves to higher Q (smaller structures). This weak peak is likely due to formation of pure fullerene regions which repel polymer aggregates and decrease in size as polymer is added. Clustered polymer aggregates may also be contributing to this peak. From $20-30 \% \mathrm{PC}_{71} \mathrm{BM}$, scattering in the region becomes less intense and peaks become less distinct. Polymer aggregates merge into larger domains while fullerene regions become smaller. At $10 \% \mathrm{PC}_{71} \mathrm{BM}$, little structure remains, because fullerene fills in gaps between polymer regions without a preferential cluster size. An illustration of these changes is provided in Figure $7 \mathrm{~b})$.

\section{DISCUSSION}

Previous work on the solution conformation of the (2EH/C8): $\mathrm{PC}_{71} \mathrm{BM}$ system observes a significant amount of solution aggregation of this polymer which determines the final morphology of the blend. Previous work further proposes that as the chlorobenzene (solvent) evaporates, (2EH/C8) forms a fibrillar network that controls the formation of $\mathrm{PC}_{71} \mathrm{BM}$ aggregates which remain solubilized in the slower-evaporating chloronaphthalene (additive) (13). In this section, we will examine both these findings in light of our data: first focusing on the aggregation behavior in solution, and then on the morphology as a whole.

In the "Polymer orientation..." section, we observe that decreasing the polymer concentration in the casting solvent makes the film progressively more edge-on: from an $18^{\circ}$ orientation in the neat $\left(0 \% \mathrm{PC}_{71} \mathrm{BM}\right)$ film to a $57^{\circ}$ orientation in the $90 \% \mathrm{PC}_{71} \mathrm{BM}$ film. In particular, $\mathrm{PC}_{71} \mathrm{BM}$ concentrations above $60 \%$ have the most dramatic effect, 
which is equivalent with the solution polymer concentration decreasing below $8 \mathrm{mg} / \mathrm{mL}$. Other literature has shown that neat films of $(\mathbf{2 E H} / \mathbf{C 8})$ become more edgeon when the casting solution concentration is decreased (14\% to $64 \%$ edge-on when concentration changes from 10 $\mathrm{mg} / \mathrm{mL}$ to $1 \mathrm{mg} / \mathrm{mL}$ ) (71). Furthermore, face-on orientation decreased when the casting solution was heated from $50^{\circ} \mathrm{C}$ to $130^{\circ} \mathrm{C}(72)$. Thus, interfering with polymer aggregation in solution, either by decreasing concentration or increasing temperature, decreases face-on orientation. These results imply that polymer that is already aggregated in solution orients face-on in the cast film, while polymer that crystallizes rapidly during the drying process is oriented isotropically or edge-on. This confirms the importance of solution aggregation on final morphology that is observed in (13).

Despite the decrease in solution aggregation expected for $>60 \% \mathrm{PC}_{71} \mathrm{BM}$ films, we still observe a preferential 10-20 $\mathrm{nm}$ polymer domain size in these films in the "Domain formation..." section. This suggests that the polymer has a strong preference to self-assemble into aggregates of this size, whether the assembly occurs in solution prior to casting or more rapidly during the casting process. This preferential aggregation may be the key to the good performance of this system. It explains why domain sizes remain small in the $(\mathbf{2} \mathbf{E H} / \mathbf{C 8})$ system despite its high degree of crystallization compared to the other three sidechain combinations.

Figure 7.a) RSoXS results from a blend ratio series of PBDTTPD(2EH/C8):PC ${ }_{71} \mathrm{BM}$ films at $284.2 \mathrm{eV}$ shifted for ease of comparison. Curves normalized by incident beam intensity and thickness, and equivalent curves at 270 eV, are shown in Figure S6. b) Schematic illustration of the microstructure of solid films of $\operatorname{PBDTTPD}(2 \mathbf{E H} / \mathbf{C 8}): \mathrm{PC}_{71} \mathrm{BM}$ with varying blend concentrations. Light blue circles represent 5-10 nm self-assembled polymer crystallites and dark red represents the aggregated fullerene matrix which fills in regions in between polymer crystallites.

In addition to a constant 10-20 nm polymer domain size, we observe a larger length scale structure which we attribute to fullerene aggregates. We speculate that the existence of a preferential length scale for fullerene structure with as much as $80 \% \mathrm{PC}_{71} \mathrm{BM}$ indicates that the small polymer domains are not uniformly dispersed within the fullerene matrix, but instead may cluster into a "skin" around fullerene regions. This observation is consistent with the fibrillar polymer network proposed in (13), and explains how the $10-20 \mathrm{~nm}$ polymer aggregates form an interconnecting network in the optimized device to allow good charge transport. This structure is reminiscent of that seen in $\mathrm{PTB}_{7}: \mathrm{PC}_{71} \mathrm{BM}$ systems made without solvent additive, in which 100-200 nm fullerene-enriched domains were separated by a "skin" of finely mixed material. The large domains in that system are detrimental to charge extraction (73). Our (2EH/C8) system may avoid these losses due to the phase purity of fullerene regions and polymer skin.

The constant domain length scales with changing blend ratios has been seen before. In (74), RSoXS of blade-coated $\mathrm{P}_{3} \mathrm{HT}: \mathrm{PCBM}$ and $\mathrm{P}_{3} \mathrm{HT}: \mathrm{PNDIT}$ (all-polymer) was compared for five blend ratios between 1:9 and 9:1. Both showed a two-length-scale system similar to our films. In $\mathrm{P}_{3} \mathrm{HT}: \mathrm{PCBM}$, the small domains systematically changed size with blend ratio with a maximum domain size at 7:3. However, in $\mathrm{P}_{3} \mathrm{HT}$ :PNDIT the shoulder in the scattering pattern at high Q remained unchanged between 9:1 and 1:9 blends, similarly to our system. It was also noted in this work that $\mathrm{P}_{3} \mathrm{HT}$ :PNDIT had a smaller amount of mixed phase than $\mathrm{P}_{3} \mathrm{HT}$ :PCBM, which was determined to enable the small domain sizes. While not conclusive, this is suggestive of a correlation between the self-assembly into small aggregates and a lack of mixed phase. In another example, the two polymers in (65) have significant amounts of mixed phase and their RSoXS patterns show dramatic evolution with fullerene loading between 20 and
$80 \%$. On the other hand, the small molecule $\mathrm{X}_{2}$ also does not form a mixed phase but does show changes to domain sizes measured by RSoXS as the ratio of $\mathrm{X}_{2}: \mathrm{PC}_{61} \mathrm{BM}$ is changed (5). This can be explained by the stronger aggregation of small molecules compared to polymers: self-assembly is not necessary for preventing fullerene mixing when the small molecule has a higher aggregation propensity.

If a lack of molecular mixing is correlated with small domain sizes, why does $(\mathbf{C} \mathbf{1 4} / \mathbf{C 8})$ have the highest degree of mixing but a similar RSoXS pattern to (2EH/C8) (Figure 2)? We speculate that the gelation of $\left(\mathbf{C}_{14} / \mathbf{C 8}\right)$, discussed in the "Device Performance" section, plays a role in encouraging the formation of a fibrillar structure similar to that of $(\mathbf{2} \mathbf{E H} / \mathbf{C 8})$. Aggregates of $\left(\mathbf{C}_{14} / \mathbf{C 8}\right)$ are less crystalline due to steric hindrance but maintain crosslinks, allowing intermixing with $\mathrm{PC}_{71} \mathrm{BM}$ without breaking the interconnected polymer network. Further investigation of $(\mathbf{C} \mathbf{1 4} / \mathbf{C 8})$ could test this hypothesis but is beyond the scope of this text.

\section{CONCLUSIONS}

From this systematic study, we can make several conclusions regarding the morphology of PBDTTPD on several length scales and its interaction with $\mathrm{PC}_{71} \mathrm{BM}$. In this set of materials, sidechains significantly affect all the figures of merit in OPV devices, changing the PCE by up to $4 \mathrm{x}$. The optimized device, with a $(\mathbf{2 E H} / \mathbf{C 8})$ sidechain combination, demonstrates the $10-20 \mathrm{~nm}$ domain sizes which are beneficial to charge extraction. This domain structure is primarily achieved by putting a $\mathrm{C} 8$ sidechain on $\mathbf{R}_{\mathbf{2}}$ (TPD) instead of $2 \mathrm{EH}$. The optimized material also has a predominantly face-on orientation, high polymer crystallinity, and negligible polymer/fullerene mixed phase. This structure is likely achieved through the selfassembly of polymers into 10-20 $\mathrm{nm}$ aggregates in solution, which form a fibrillar network as $\mathrm{PC}_{71} \mathrm{BM}$ is added. The lack 
of mixed phase in a high performing polymer/fullerene device is interesting in light of literature suggesting that mixed phase has a crucial role in charge separation.

The addition of $\mathrm{PC}_{71} \mathrm{BM}$ instigates $\mathrm{a} \sim 2 \mathrm{x}$ enhancement in polymer crystallinity for all sidechain combinations. The amount of mixed phase depends on the sidechains. The larger ( $\left.\mathrm{C}_{14}\right)$ sidechain on $\mathbf{R}_{\mathbf{1}}$ and to a lesser extent the branched ( $2 \mathrm{EH})$ on $\mathbf{R}_{2}$ encourage mixing. The degree of mixing does not have an obvious effect on the device performance. The device FF correlates with the orientation, with more face-on films achieving better FF and $\mathrm{J}_{\mathrm{sc}}$ than edge-on films. While literature predicts that larger and/or branched sidechains result in face-on orientation, we observe the opposite trend for the $\mathbf{R}_{2}$ sidechain $(\mathrm{C} 8$ vs $2 \mathrm{EH})$ in this system. This highlights the important role of the location of sidechain attachment on the polymer backbone.

\section{ASSOCIATED CONTENT}

Supporting Information. Contains 14 figures and 5 tables, detailed methods, additional measurements relevant to discussion, and intermediate peak fitting results used to reduce data. This material is available free of charge via the Internet at http://pubs.acs.org.

\section{AUTHOR INFORMATION}

\section{Corresponding Author}

* mftoney@slac.stanford.edu

\section{Present Addresses}

4 Department of Chemistry and Centre for Plastic

Electronics, Imperial College London, London, $\mathrm{SW}_{7} 2 \mathrm{AZ}$, United Kingdom

${ }^{5}$ School of Chemistry and Environment, South China Normal University, Guangzhou 510006, P. R. China

${ }^{6}$ TNO, 2595 DA The Hague, Netherlands

7 School of Polymer Science and Engineering, University of Southern Mississippi, 118 College Drive, Hattiesburg, MS 39406-ooo1, United States

\section{Author Contributions}

All authors have given approval to the final version of the manuscript.

\section{Funding Sources}

This work was supported by the Office of Naval Research NDSEG fellowship (VS). Work was partially supported by the Department of the Navy, Office of Naval Research Award No. Nooo14-14-1-0580 (SO, MFT). MB, MN, SL, and PB were supported by the King Abdullah University of Science and Technology (KAUST) Office of Sponsored Research (OSR) under Award No. CRG_R2_13_BEAU_KAUST_1 and concurrently supported under Baseline Research Funding from KAUST. Use of the Stanford Synchrotron Radiation Lightsource, SLAC National Accelerator Laboratory, is supported by the U.S. Department of Energy, Office of Science, Office of Basic Energy Sciences under Contract No. DE-AC02-76SFoo515. Part of this work was performed at the
Stanford Nano Shared Facilities (SNSF), supported by the National Science Foundation under award ECCS-1542152.

\section{ACKNOWLEDGMENT}

The authors would like to thank Zhipeng Kan, Tzu-Yen Huang, Maged Abdelsamie, and Sebastian Schneider for helpful discussion.

\section{ABBREVIATIONS}

OPV, organic photovoltaic; BHJ, bulk heterojunction; PBDTTPD, poly(benzo[1,2-b:4,5-b']dithiophene-altthieno[3,4-c]pyrrole-4,6-dione); 2EH, 2-ethylhexyl (2EH); C8, octyl; $\mathrm{C}_{14}$, tetradecyl; $\mathrm{PC}_{71} \mathrm{BM}$, [6,6]-Phenyl-C71-butyric acid methyl ester; JSC, short-circuit current; $V_{\mathrm{OC}}$, open-circuit voltage; FF, fill factor; PCE, power conversion efficiency; RSoXS, resonant soft $x$-ray scattering; GIWAXS, grazing incidence wide angle $\mathrm{x}$-ray scattering; HR-TEM, high resolution transmission electron microscopy.

\section{REFERENCES}

1. Zhang, S.; Qin, Y.; Zhu, J.; Hou, J. Over 14\% Efficiency in Polymer Solar Cells Enabled by a Chlorinated Polymer Donor. Adv. Mater. 2018, 30, 1800868.

2. Bartelt, J. A.; Beiley, Z. M.; Hoke, E. T.; Mateker, W. R.; Douglas, J. D.; Collins, B. A.; Tumbleston, J. R.; Graham, K. R.; Amassian, A.; Ade, H.; Fréchet, J. M. J.; Toney, M. F.; McGehee, M. D. The Importance of Fullerene Percolation in the Mixed Regions of Polymer-Fullerene Bulk Heterojunction Solar Cells. Adv. Energy Mater. 2013, 3, 364-374.

3. Li, N.; Perea, J. D.; Kassar, T.; Richter, M.; Heumueller, T.; Matt, G. J.; Hou, Y.; Güldal, N. S.; Chen, H.; Chen, S.; Langner, S.; Berlinghof, M.; Unruh, T.; Brabec, C. J. Abnormal strong burnin degradation of highly efficient polymer solar cells caused by spinodal donor-acceptor demixing. Nat. Commun. 2017, 8, 14541. 4. Oosterhout, S. D.; Savikhin, V.; Zhang, J.; Zhang, Y.; Burgers, M. A.; Marder, S. R.; Bazan, G. C.; Toney, M. F. Mixing Behavior in Small Molecule:Fullerene Organic Photovoltaics. Chem. Mater. 2017, 29, 3062-3069.

5. Oosterhout, S. D.; Savikhin, V.; Burgers, M. A.; Zhang, J.; Zhang, Y.; Marder, S. R.; Bazan, G. C.; Toney, M. F. Absence of Mixed Phase in Organic Photovoltaic Active Layers Facilitates Use of Green Solvent Processing. J. Phys. Chem. 2018, 122, 11136-11144.

6. Bundgaard, E.; Krebs, F. C. Low band gap polymers for organic photovoltaics. Sol. Energy Mater. Sol. Cells 2007, 91, 954985 .

7. Jiang, J.-M.; Yuan, M.-C.; Dinakaran, K.; Hariharanb, A. Crystalline donor-acceptor conjugated polymers for bulk heterojunction photovoltaics. J. Mater. Chem. A 2013, 1, 4415-4422. 8. Labban, A. E.; Warnan, J.; Cabanetos, C.; Ratel, O.; Tassone, C.; Toney, M. F.; Beaujuge, P. M. Dependence of Crystallite Formation and Preferential Backbone Orientations on the Side Chain Pattern in PBDTTPD Polymers. ACS Appl. Mater. Interfaces 2014, 6, 19477-19481.

9. $\quad$ Cabanetos, C.; Labban, A. E.; Bartelt, J. A.; Douglas, J. D.; Mateker, W. R.; Fréchet, J. M. J.; McGehee, M. D.; Beaujuge, P. M. Linear Side Chains in Benzo[1,2-b:4,5-b']dithiophene-Thieno[3,4c]pyrrole-4,6-dione Polymers Direct Self-Assembly and Solar Cell Performance. J. Am. Chem. Soc. 2013, 135, 4656-4659.

10. Dyer-Smith, C.; Howard, I. A.; Cabanetos, C.; Labban, A. E.; Beaujuge, P. M.; Laquai, F. Interplay Between Side Chain Pattern, Polymer Aggregation, and Charge Carrier Dynamics in PBDTTPD:PCBM Bulk-Heterojunction Solar Cells. Adv. Energy Mater. 2015, 5, 1401778. 
11. Constantinou, I.; Lai, T.-H.; Klump, E. D.; Goswami, S.; Schanze, K. S.; So, F. Effect of Polymer Side Chains on Charge Generation and Disorder in PBDTTPD Solar Cells. ACS Appl. Mater. Interfaces 2015, 7, 26999-27005.

12. Graham, K. R.; Cabanetos, C.; Jahnke, J. P.; Idso, M. N.; Labban, A. E.; Ndjawa, G. O. N.; Heumueller, T.; Vandewal, K.; Salleo, A.; Chmelka, B. F.; Amassian, A.; Beaujuge, P. M.; McGehee, M. D. Importance of the Donor:Fullerene Intermolecular Arrangement for High-Efficiency Organic Photovoltaics. J. Am. Chem. Soc. 2014, 136, 9608-9618.

13. Bartelt, J. A.; Douglas, J. D.; Mateker, W. R.; Labban, A. E.; Tassone, C. J.; Toney, M. F.; Fréchet, J. M. J.; Beaujuge, P. M.; McGehee, M. D. Controlling Solution-Phase Polymer Aggregation with Molecular Weight and Solvent Additives to Optimize Polymer-Fullerene Bulk Heterojunction Solar Cells. Adv. Energy Mater. 2014, 4, 1301733.

14. Gao, Y.; Corre, V. M. L.; Gaïtis, A.; Neophytou, M.; Hamid, M. A.; Takanabe, K.; Beaujuge, P. M. Homo-Tandem Polymer Solar Cells with VOC $>1.8 \mathrm{~V}$ for Efficient PV-Driven Water Splitting. Adv. Mater. 2o16, 28, 3366-3373.

15. Wang, T.; Pearson, A. J.; Lidzey, D. G. Correlating molecular morphology with optoelectronic function in solar cells based on low band-gap copolymer:fullerene blends. J. Mater. Chem. C 2013, 1, 7266-7293.

16. Bin, H.; Yang, Y.; Peng, Z.; Ye, L.; Yao, J.; Zhong, L.; Sun, C.; Gao, L.; Huang, H.; Li, X.; Qiu, B.; Xue, L.; Zhang, Z. -.; Ade, H.; Li, Y. F. Effect of Alkylsilyl Side-Chain Structure on Photovoltaic Properties of Conjugated Polymer Donors. Adv. Energy Mater. 2018, 8, 1702324.

17. Li, Y.; Zou, J.; Yip, H.-L.; Li, C.-Z.; Zhang, Y.; Chueh, C.C.; Intemann, J.; Xu, Y.; Liang, P.-W.; Chen, Y.; Jen, A. K.-Y. SideChain Effect on Cyclopentadithiophene/FluorobenzothiadiazoleBased Low Band Gap Polymers and Their Applications for Polymer Solar Cells. Macromolecules 2013, 46, 5497-5503.

18. Burkhart, B.; Khlyabich, P. P.; Thompson, B. C. Influence of the Ethylhexyl Side-Chain Content on the OpenCircuit Voltage in rr-Poly(3-hexylthiophene-co-3-(2ethylhexyl)thiophene) Copolymers. Macromolecules 2012, 45, 3740-3748.

19. Li, Z.; Tsang, S.; Du, X.; Scoles, L.; Robertson, G.; Zhang, Y.; Toll, F.; Tao, Y.; Lu, J.; Ding, J. Alternating Copolymers of Cyclopenta[2,1-b;3,4-b']dithiophene and Thieno[3,4-c]pyrrole-4,6-dione for High-Performance Polymer Solar Cells. Adv. Funct. Mater. 2o11, 21, 3331-3336.

20. Gadisa, A.; Oosterbaan, W. D.; Vandewal, K.; Bolsée, J.; Bertho, S.; D'Haen, J.; Lutsen, L.; Vanderzande, D.; Manca, J. V. Effect of Alkyl Side-Chain Length on Photovoltaic Properties of Poly(3-alkylthiophene)/PCBM Bulk Heterojunctions. Adv. Funct. Mater. 2009, 19, 3300-3306.

21. Liang, Y.; Feng, D.; Wu, Y.; Tsai, S.-T.; Li, G.; Ray, C.; Yu, L. Highly Efficient Solar Cell Polymers Developed via Fine-Tuning of Structural and Electronic Properties. J. Am. Chem. Soc. 2oog, 131, 7792-7799.

22. Osaka, I.; Takimiya, K. Backbone orientation in semiconducting polymers. Polymer 2015, 59, A1-A15.

23. Yiu, A. T.; Beaujuge, P. M.; Lee, O. P.; Woo, C. H.; Toney, M. F.; Fréchet, J. M. J. Side-Chain Tunability of Furan-Containing Low-Band-Gap Polymers Provides Control of Structural Order in Efficient Solar Cells. J. Am. Chem. Soc. 2012, 134, 218o-2185.

24. Harschneck, T.; Zhou, N.; Manley, E. F.; Lou, S. J.; Yu, X.; Butler, M. R.; Timalsina, A.; Turrisi, R.; Ratner, M. A.; Chen, L. X.; Chang, R. P. H.; Facchetti, A.; Marks, T. J. Substantial photovoltaic response and morphology tuning in benzo[1,2-b:6,5- b']dithiophene (bBDT) molecular donors. Chem. Commun. 2014, 50, 4099-4101.

25. Oosterhout, S. D.; Braunecker, W. A.; Owczarczyk, Z. R.; Ayzner, A. L.; toney, M. F.; Olson, D. C.; Kopidakis, N. Molecular engineering to improve carrier lifetimes for organic photovoltaic devices with thick active layers. Org. Electron. 2017, 47, $57-65$.

26. Schroeder, B. C.; Kurosawa, T.; Fu, T.; Chiu, Y.; Mun, J.; Wang, G. N.; Gu, X.; Shaw, L.; Kneller, J. W. E.; Kreouzis, T.; Toney, M. F.; Bao, Z. Taming Charge Transport in Semiconducting Polymers with Branched Alkyl Side Chains. Adv. Funct. Mater. 2017, 27, 1701973.

27. Tessarolo, M.; Gedefaw, D.; Bolognesi, M.; Liscio, F.; Henriksson, P.; Zhuang, W.; Milita, S.; Muccini, M.; Wang, E.; Seri, M.; Andersson, M. R. Structural tuning of quinoxalinebenzodithiophene copolymers via alkyl side chain manipulation: synthesis, characterization and photovoltaic properties. J. Mater. Chem. A 2014, 2, 11162-11170.

28. McDearmon, B.; Page, Z. A.; Chabinyc, M. L.; Hawker, C. J. Organic electronics by design: the power of minor atomic and structural changes. J. Mater. Chem. C 2018, 6, 3564-3572.

29. Szarko, J. M.; Guo, J.; Liang, Y.; Lee, B.; Rolczynski, B. S.; Strzalka, J.; Xu, T.; Loser, S.; Marks, T. J.; Yu, L.; Chen, L. X. When Function Follows Form: Effects of Donor Copolymer Side Chains on Film Morphology and BHJ Solar Cell Performance. Adv. Mater. 2010, 22, 5468-5472.

30. Mondal, R.; Ko, S.; Verploegen, E.; Becerril, H. A.; Toney, M. F.; Bao, Z. Side chain engineering of fused aromatic thienopyrazine based low band-gap polymers for enhanced charge carrier mobility. J. Mater. Chem. 2011, 21, 1537-1543.

31. Rumer, J. W.; Hor, C. K. L.; Meager, I.; Yau, C. P.; Huang, Z.; Nielsen, C. B.; Watkins, S. E.; Bronstein, H.; McCulloch, I. Alkyl side-chain branching point effects in thieno[3,4-c]pyrrole-4,6dione copolymers. J. Org. Semic. 2013, 1, 30-35.

32. Osaka, I.; Saito, M.; Koganezawa, T.; Takimiya, K. Thiophene-Thiazolothiazole Copolymers: Significant Impact of Side Chain Composition on Backbone Orientation and Solar Cell Performances. Adv. Mater. 2014, 26, 331-338.

33. Wood, S.; Kim, J.-H.; Hwang, D.-H.; Kim, J.-S. Effects of Fluorination and Side Chain Branching on Molecular Conformation and Photovoltaic Performance of Donor-Acceptor Copolymers. Chem. Mater. 2015, 27, 4196-4204.

34. Gao, K.; Miao, J.; Xiao, L.; Deng, W.; Kan, Y.; Liang, T.; Wang, C.; Huang, F.; Peng, J.; Cao, Y.; Liu, F.; Russell, T. P.; Wu, H.; Peng, X. Multi-Length-Scale Morphologies Driven by Mixed Additives in Porphyrin-Based Organic Photovoltaics. Adv. Mater. 2016, 28, 4727-4733.

35. Strawhecker, K. E.; Kumar, S. K. The Critical Role of Solvent Evaporation on the Roughness of Spin-Cast Polymer Films. Macromolecules 2oo1, 34, 4669-4672.

36. Aïch, B. R.; Lu, J.; Beaupré, S.; Leclerc, M.; Tao, Y. Control of the active layer nanomorphology by using co-additives towards high-performance bulk heterojunction solar cells. Org. Electron. 2012, 13, 1736-1741.

37. Liu, Y.; Zhao, J.; Li, Z.; Mu, C.; Ma, W.; Hu, H.; Jiang, K.; Lin, H.; Ade, H.; Yan, H. Aggregation and morphology control enables multiple cases of high-efficiency polymer solar cells. Nat. Commun. 2014, 5, 5293.

38. $\mathrm{Hu}, \mathrm{X}$; Yi, C.; Wang, M.; Hsu, C.; Liu, S.; Zhang, K.; Zhong, C.; Huang, F.; Gong, X.; Cao, Y. High-Performance Inverted Organic Photovoltaics with Over $1-\mu \mathrm{m}$ Thick Active Layers. Adv. Energy Mater. 2014, 4, 1400378.

39. Liang, R.-Z.; Zhang, Y.; Savikhin, V.; Babics, M.; Kan, Z.; Wohlfahrt, M.; Lopatin, S.; Wehbe, N.; Liu, S.; Duan, T.; Toney, 
M. F.; Laquai, F.; Beaujuge, P. M. Higher Mobility and Carrier Lifetimes in Solution-Processable Small-Molecule Ternary Solar Cells with $11 \%$ Efficiency. Adv. Energy Mater. In revision 2018 (DOI: 10.1002/aenm.201802836).

40. Huang, W. Y.; Huang, P. T.; Han, Y. K.; Lee, C. C.; Hsieh, T. L.; Chang, M. Y. Aggregation and Gelation Effects on the Performance of Poly(3-hexylthiophene)/Fullerene Solar Cells. Macromolecules 2008, 41, 7485-7489.

41. Schmidt-Hansberg, B.; Sanyal, M.; Klein, M. F. G.; Pfaff, M.; Schnabel, N.; Jaiser, S.; Vorobiev, A.; Müller, E.; Colsmann, A.; Scharfer, P.; Gerthsen, D.; Lemmer, U.; Barrena, E.; Schabel, W. Moving through the Phase Diagram: Morphology Formation in Solution Cast Polymer-Fullerene Blend Films for Organic Solar Cells. ACS Nano 2011, 5, 8579-859o.

42. Fu, T.; Li, Z.; Zhang, Z.; Zhang, X.; Wang, F. Supramolecular Cross-Linking and Gelation of Conjugated Polycarbazoles via Hydrogen Bond Assisted Molecular Tweezer/Guest Complexation. Macromolecules 2017, 50, 75177525 .

43. Li, H.; Buesen, D.; Williams, R.; Henig, J.; Stapf, S.; Mukherjee, K.; Freier, E.; Lubitz, W.; Winkler, M.; Happe, T.; Plumeré, N. Preventing the coffee-ring effect and aggregate sedimentation by in situ gelation of monodisperse materials. Chem. Sci. 2018, Advance Article (DOI: 10.1039/c8sco3302a).

44. Gann, E.; Young, A. T.; Collins, B. A.; Yan, H.; Nasiatka, J.; Padmore, H. A.; Ade, H.; Hexemer, A.; Wang, C. Soft x-ray scattering facility at the Advanced Light Source with real-time data processing and analysis. Rev. Sci. Instrum. 2012, 83, 045110.

45. $\quad$ Song, J.; Zhang, M.; Yuan, M.; Qian, Y.; Sun, Y.; Liu, F. Morphology Characterization of Bulk Heterojunction Solar Cells. Small Methods 2018, 2, 1700229.

46. Beaucage, G. Approximations Leading to a Unified Exponential/Power-Law Approach to Small-Angle Scattering. J. Appl. Cryst. 1995, 28, 717-728.

47. Mikhnenko, O. V.; Blom, P. W. M.; Nguyen, T.-Q. Exciton diffusion in organic semiconductors. Energy Environ. Sci. 2015, 8, 1867-1888.

48. Zhou, C.; Zhang, G.; Zhong, C.; Jia, X.; Luo, P.; Xu, R.; Gao, K.; Jiang, X.; Liu, F.; Russell, T. P.; Huang, F.; Cao, Y. Toward High Efficiency Polymer Solar Cells: Influence of Local Chemical Environment and Morphology. Adv. Energy Mater. 2017, 7, 1601081 .

49. Wang, T.; Ravva, M. K.; Brédas, J. Impact of the Nature of the Side-Chains on the Polymer-Fullerene Packing in the Mixed Regions of Bulk Heterojunction Solar Cells. Adv. Funct. Mater. 2016, 26, 5913-5921.

50. Mayer, A. C.; Toney, M. F.; Scully, S. R.; Rivnay, J.; Brabec, C. J.; Scharber, M.; Koppe, M.; Heeney, M.; McCulloch, I.; McGehee, M. D. Bimolecular Crystals of Fullerenes in Conjugated Polymersand the Implications of Molecular Mixing for Solar Cells. Adv. Funct. Mater. 2009, 19, 1173-1179.

51. Buchaca-Domingo, E.; Ferguson, A. J.; Jamieson, F. C.; McCarthy-Ward, T.; Shoaee, S.; J., R. T.; Reid, O. G.; L., Y.; M.-B., M.; Pfannmöller, M.;.; Kopidakis, N.; Portale, G.; Amassian, A.; Heeney, M.; Ade, H.; Rumbles, G.; Durrant, J. R.; Stingelin, N. Additive-assisted supramolecular manipulation of polymer:fullerene blend phase morphologies and its influence on photophysical processes. Mater. Horiz. 2014, 1, 270-279.

52. Meager, I.; Ashraf, R. S.; Mollinger, S.; Schroeder, B. C.; Bronstein, H.; Beatrup, D.; Vezie, M. S.; Kirchartz, T.; Salleo, A.; Nelson, J.; McCulloch, I. Photocurrent Enhancement from Diketopyrrolopyrrole Polymer Solar Cells through Alkyl-Chain Branching Point Manipulation. J. Am. Chem. Soc. 2013, 135, 11537-11540.
53. Gu, Y.; Wang, C.; Russell, T. P. Multi-Length-Scale Morphologies in PCPDTBT/PCBM Bulk-Heterojunction Solar Cells. Adv. Energy Mater. 2012, 2, 683-69o.

54. Guo, X.; Zhou, N.; Lou, S. J.; Smith, J.; Tice, D. B.; Hennek, J. W.; Ortiz, R. P.; Navarrete, J. T. L.; Li, S.; Strzalka, J.; Chen, L. X.; Chang, R. P. H.; Facchetti, A.; Marks, T. J. Polymer solar cells with enhanced fill factors. Nat. Photonics 2013, 7, 825833 .

55. $\quad$ Rogers, J. T.; Schmidt, K.; Toney, M. F.; Kramer, E. J.; Bazan, G. C. Structural Order in Bulk Heterojunction Films Prepared with Solvent Additives. Adv. Mater. 2011, 23, 2284-2288. 56. Mateker, W. R.; Heumueller, T.; Cheacharoen, R.; Sachs-Quintana, I. T.; McGehee, M. D. Molecular Packing and Arrangement Govern the Photo-Oxidative Stability of Organic Photovoltaic Materials. Chem. Mater. 2015, 27, 6345-6353.

57. Toney, M. F.; Brennan, S. Observation of the effect of refraction on $\mathrm{x}$ rays diffracted in a grazing-incidence asymmetric Bragg geometry. Phys. Rev. B 1989, 39, 7963-7966.

58. Crouch, D. J.; Skabara, P. J.; Lohr, J. E.; McDouall, J. J. W.; Heeney, M.; McCulloch, I.; Sparrowe, D.; Shkunov, M.; Coles, S. J.; Horton, P. N.; Hursthouse, M. B. Thiophene and Selenophene Copolymers Incorporating Fluorinated Phenylene Units in the Main Chain: Synthesis, Characterization, and Application in Organic Field-Effect Transistors. Chem. Mater. 2005, 17, 6567-6578.

59. Hartnett, P. E.; Timalsina, A.; Matte, H. S. S. R.; Zhou, N.; Guo, X.; Zhao, W.; Facchetti, A.; Chang, R. P. H.; Hersam, M. C.; Wasielewski, M. R.; Marks, T. J. Slip-Stacked Perylenediimides as an Alternative Strategy for High Efficiency Nonfullerene Acceptors in Organic Photovoltaics. J. Am. Chem. Soc. 2014, 136, $16345^{-16356 . ~}$

6o. $\quad$ Rivnay, J.; Jimison, L. H.; Northrup, J. E.; Toney, M. F.; Noriega, R.; Lu, S.; Marks, T. J.; Facchetti, A.; Salleo, A. Large modulation of carrier transport by grain-boundary molecular packing and microstructure in organic thin films. Nat. Mater. 2009, 8, 952-958.

61. J.Hale, B.; Elshobaki, M.; Gebhardt, R.; Wheeler, D.; Stoffer, J.; Tomlinson, A.; Chaudhary, S.; Jeffries-EL, M. Evaluating the influence of heteroatoms on the electronic properties of aryl[3,4-c]pyrroledione based copolymers. Polymer 2017, 109, 8592.

62. Ran, N. A.; Roland, S.; Love, J. A.; Savikhin, V.; Takacs, C. J.; Fu, Y.-T.; Li, H.; Coropceanu, V.; Liu, X.; Brédas, J.-L.; Bazan, G. C.; Toney, M. F.; Neher, D.; Nguyen, T.-Q. Impact of interfacial molecular orientation on radiative recombination and charge generation efficiency. Nat. Commun. 2017, 8, 79.

63. Hoppe, H.; Sariciftci, N. S. Morphology of polymer/fullerene bulk heterojunction solar cells. J. Mater. Chem. 2oo6, 16, 45-61.

64. Guilbert, A. A. Y.; Cabral, J. T. Impact of solution phase behaviour and external fields on thin film morphology: PCBM and RRa-P ${ }_{3}$ HT model system. Soft Matter 2o17, 13, 827-835.

65. Tumbleston, J. R.; Yang, L.; You, W.; Ade, H. Morphology linked to miscibility in highly amorphous semiconducting polymer/fullerene blends. Polymer 2014, 55, 48844889 .

66. Ravva, M. K.; Wang, T.; Bredas, J.-L. Nature of the Binding Interactions between Conjugated Polymer Chains and Fullerenes in Bulk Heterojunction Organic Solar Cells. Chem. Mater. 2016, 28, 8181-8189.

67. Hammond, M. R.; Kline, R. J.; Herzing, A. A.; Richter, L. J.; Germack, D. S.; Ro, H.-W.; Soles, C. L.; Fischer, D. A.; Xu, T.; Yu, L.; Toney, M. F.; DeLongchamp, D. M. Molecular Order in 
High-Efficiency Polymer/Fullerene Bulk Heterojunction Solar Cells. ACS Nano 2011, 5, 8248-8257.

68. Turner, S. T.; Pingel, P.; Steyrleuthner, R.; Crossland, E. J. W.; Ludwigs, S.; Neher, D. Quantitative Analysis of Bulk Heterojunction Films Using Linear Absorption Spectroscopy and Solar Cell Performance. Adv. Funct. Mater. 2011, 21, 4640-4652.

69. Huang, T.-Y.; Yan, H.; Abdelsamie, M.; Savikhin, V.; Schneider, S. A; Ran, N. A.; Nguyen, T.-Q.; Bazan, G. C.; Toney, M. F. Fullerene derivative induced morphology of bulk heterojunction blends: PIPCP:PC61BM. J. Mater. Chem. A Submitted 2018 (ID: TA-ART-10-2018-009677).

70. $\quad$ Hernandez, J. L.; Deb, N.; Wolfe, R. M. W.; Lo, C. K.; Engmann, S.; Richter, L. J.; Reynolds, J. R. Simple transfer from spin coating to blade coating through processing aggregated solution. J. Mater. Chem. A 2017, 5, 20687.

71. O'Hara, K. A. Structural Ordering of Semiconducting Polymers and Small-Molecules for Organic Electronics. PhD Thesis, University of California, Santa Barbara, Santa Barbara, CA, USA, 2017
72. Tournebize, A.; Gardette, J.-L.; Taviot-Guého, C.; Bégué, D.; Arnaud, M. A.; Dagron-Lartigau, C.; Medlej, H.; Hiorns, R. C.; Beaupré, S.; Leclerc, M.; Rivaton, A. Is there a photostable conjugated polymer for efficient solar cells? Polym. Degrad. Stab. 2015, 112, 175-184.

73. Hedley, G. J.; Ward, A. J.; Alekseev, A.; Howells, C. T.; Martins, E. R.; Serrano, L. A.; Cooke, G.; Ruseckas, A.; Samuel, I. D. W. Determining the optimum morphology in highperformance polymer-fullerene organic photovoltaic cells. Nat. Commun. 2013, 4, 2867.

74. Gu, X.; Yan, H.; Kurosawa, T.; Schroeder, B. C.; Gu, K. L.; Zhou, Y.; To, J. W. F.; Oosterhout, S. D.; Savikhin, V.; MolinaLopez, F.; Tassone, C. J.; Mannsfeld, S. C. B.; Wang, C.; Toney, M. F.; Bao, Z. Comparison of the Morphology Development of Polymer-Fullerene and Polymer-Polymer Solar Cells during Solution-Shearing Blade Coating. Adv. Energy Mater. 2016, 6, 1601225 . 
a)
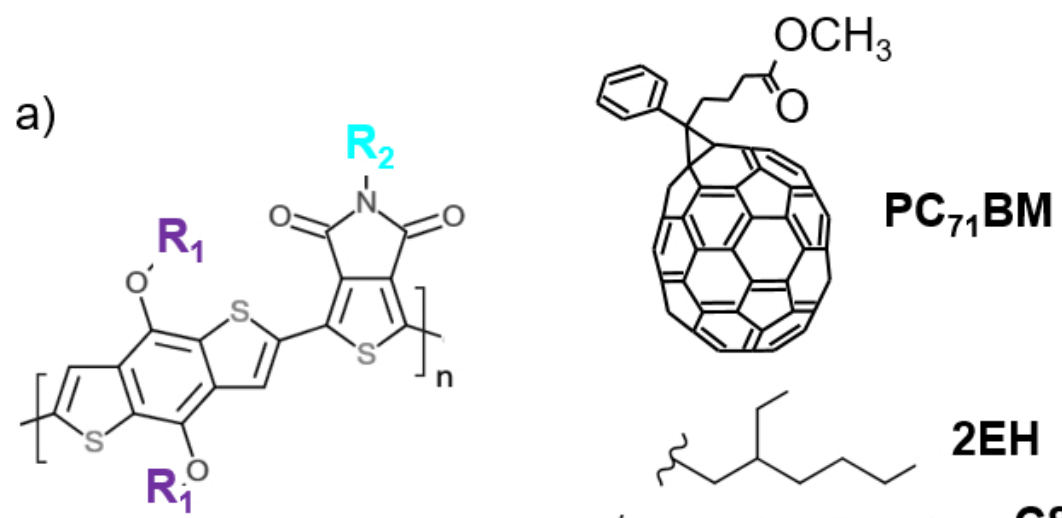

$\operatorname{PBDTTPD}\left(\mathrm{R}_{1} / \mathrm{R}_{2}\right)$ b)

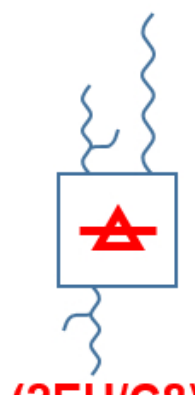

(2EH/C8)

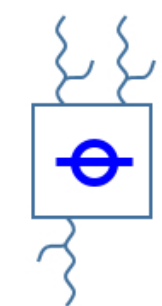

(2EH/2EH)

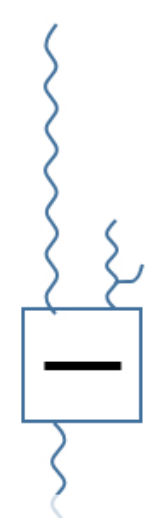

(C14/2EH)

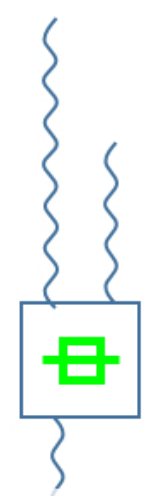

(C14/C8)

Figure 1. a) Chemical structures of PBDTTPD, sidechains, and $\mathrm{PC}_{71} \mathrm{BM}$. b) Illustrations of the four sidechain combinations studied here, where squares represent a backbone unit and lines represent sidechains of varying branching and length. The color and marker shape for each combination is consistent throughout this work for ease of comparison: $(2 \mathrm{EH} / \mathbf{C 8})=$ red triangle, $(\mathbf{2 E H} / \mathbf{2 E H})=$ blue circle, $(\mathbf{C 1 4} / \mathbf{2 E H})=$ black no marker, $(\mathbf{C 1 4} / \mathbf{C 8})=$ green square.

$129 \times 147 \mathrm{~mm}(150 \times 150 \mathrm{DPI})$ 

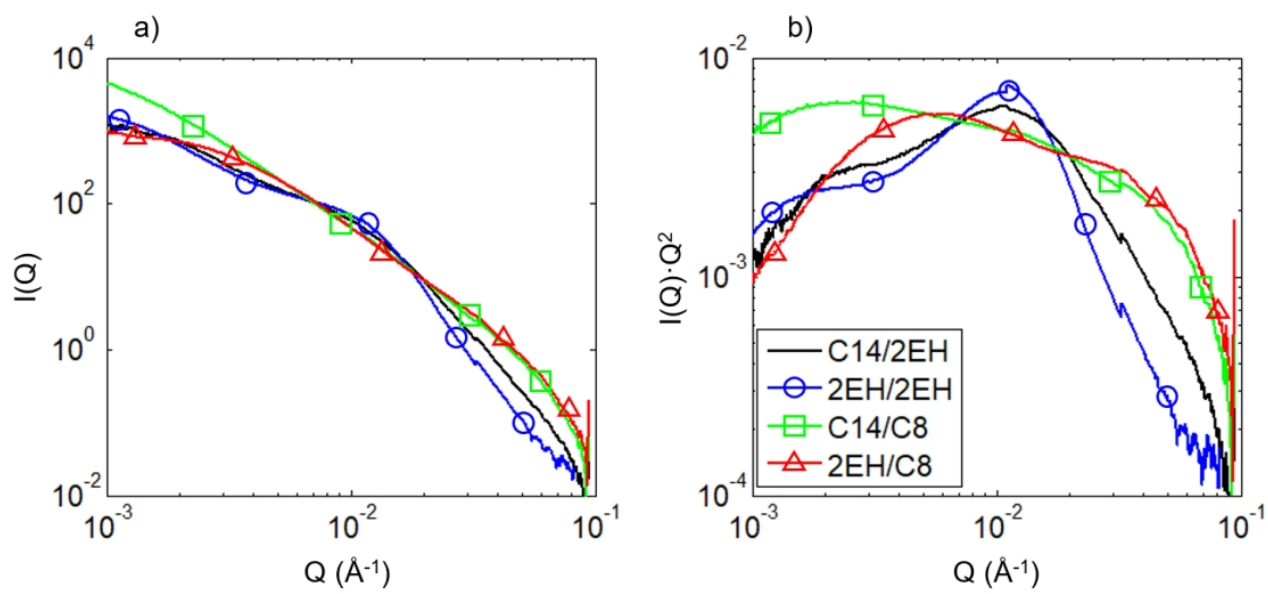

Figure 2. RSoXS data from PBDTTPD:PC 71 BM (1:1.5) blend films at an incident energy of 284.2 eV. Detector intensity $I(Q)$ is shown in a) while $I(Q) \cdot Q^{2}$ is plotted in $b$ ). For ease of comparison, data is arbitrarily vertically offset (multiplied by a scaling factor) here. Data normalized by the incident intensity and additional data can be found in Figure S4-S5.

$252 \times 119 \mathrm{~mm}(150 \times 150 \mathrm{DPI})$ 

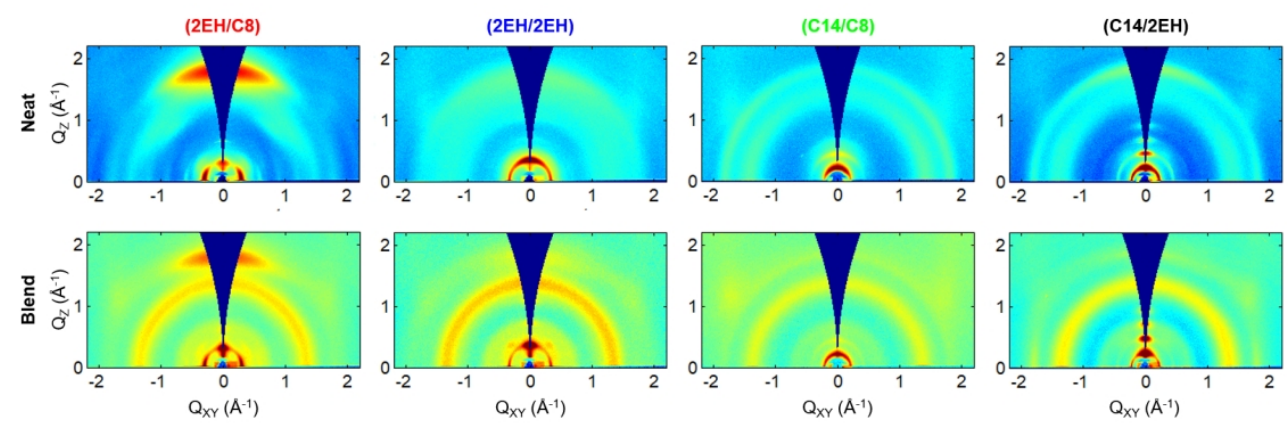

Figure 3. GIWAXS patterns for neat polymers (top) and optimized blends (60\% $\mathrm{PC} \mathrm{71}_{71} \mathrm{BM}$ ) (bottom) with four different sidechain configurations, as labeled.

$303 \times 101 \mathrm{~mm}(150 \times 150 \mathrm{DPI})$ 
a)

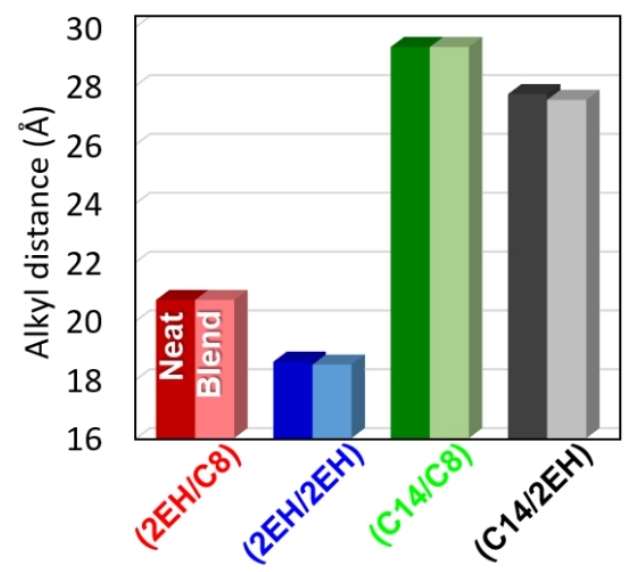

b)

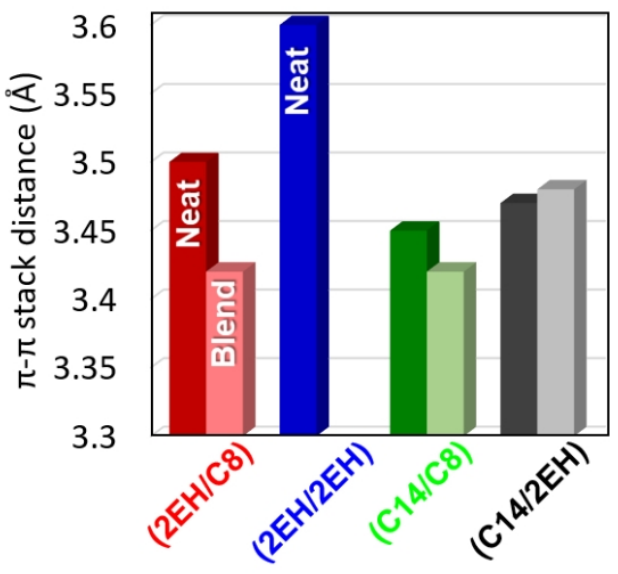

Figure 4. a) Comparison of alkyl stacking distances of neat and blend films; neat films are shown in a darker color. b) Comparison of $\Pi-\pi$ stacking distances.

$200 \times 103 \mathrm{~mm}(150 \times 150 \mathrm{DPI})$ 

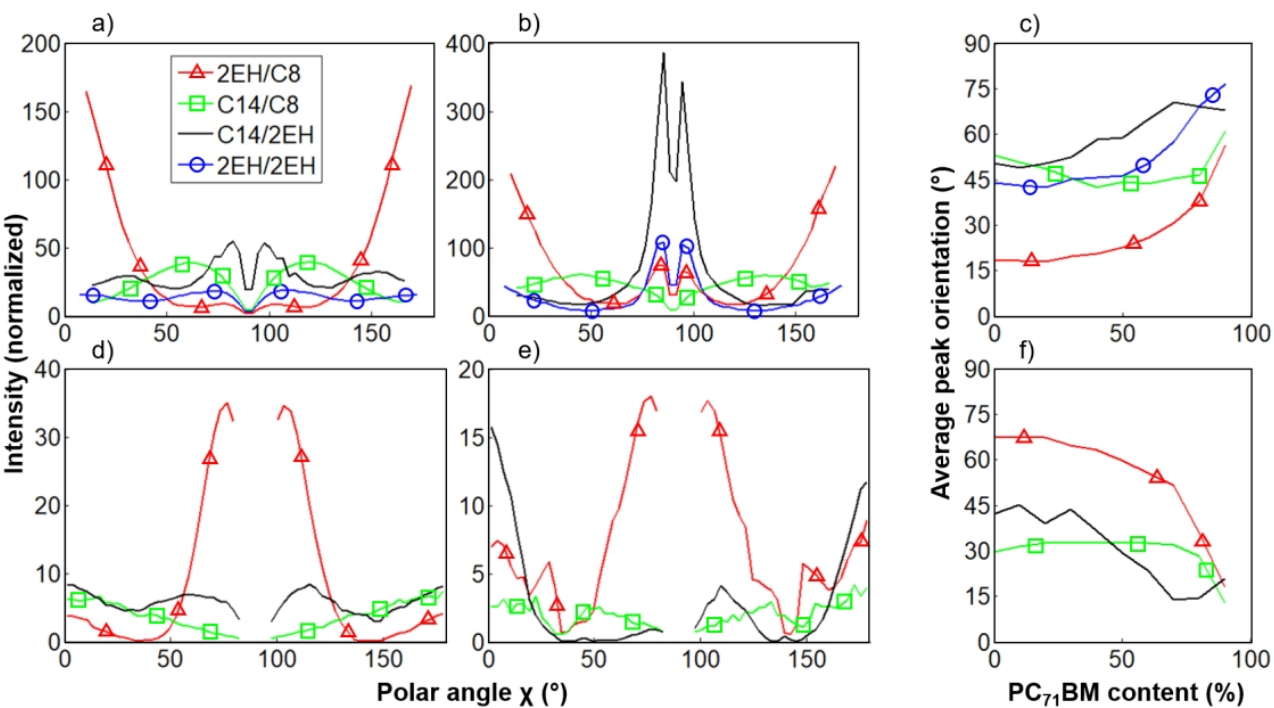

Figure 5. a,b,d,e) Pole figures with $\sin (\mathrm{X})$ correction, where 0 and $180^{\circ}$ are in-plane and $90^{\circ}$ is out-of-plane polar angle. a,b) Alkyl peak; d,e) $\Pi-n$ stacking peak; a,d) Neat films; b,e) blend films with $60 \% \mathrm{PC}_{71} \mathrm{BM}$, corresponding to devices. The $\Pi-\Pi$ stacking peak of (2EH/2EH) was difficult to isolate from background due to a large peak width, so it has been omitted. $c$, $f$ ) Average peak orientation versus $P C_{71} B M$ content for four sidechains, calculated from c) alkyl peak and f) п-п stacking peak.

$291 \times 163 \mathrm{~mm}(150 \times 150 \mathrm{DPI})$ 

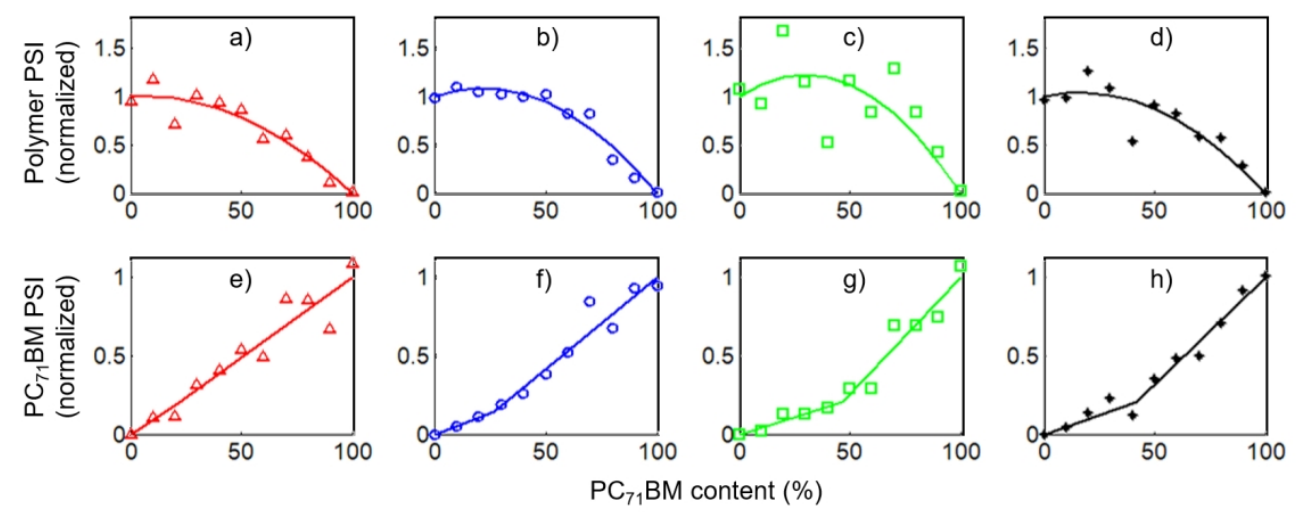

Figure 6. PSI from peak fitting as a function of $\mathrm{PC}_{71} \mathrm{BM}$ content, used to calculate the $\mathrm{PC}_{71} \mathrm{BM}$-induced enhancement of polymer crystallinity and the amount of mixed phase. Symbols show data and solid lines are smoothing functions used to calculate crystallinity enhancement and amount of mixed phase in Table 2. a-d) show the polymer alkyl peak intensity smoothed with a quadratic function, normalized by the value of the neat polymer film; e-h) show the $\mathrm{PC}_{71} \mathrm{BM}$ peak intensity smoothed with a two-part line, normalized by the value of the neat $\mathrm{PC}_{71} \mathrm{BM}$. Data is given for a,e) (2EH/C8); b,f) (2EH/2EH); c,g) (C14/C8); d,h) $(\mathbf{C 1 4 / 2 E H})$. The large variance in (C14/C8) (c) is due to thickness uncertainty arising from film roughness. 
a)

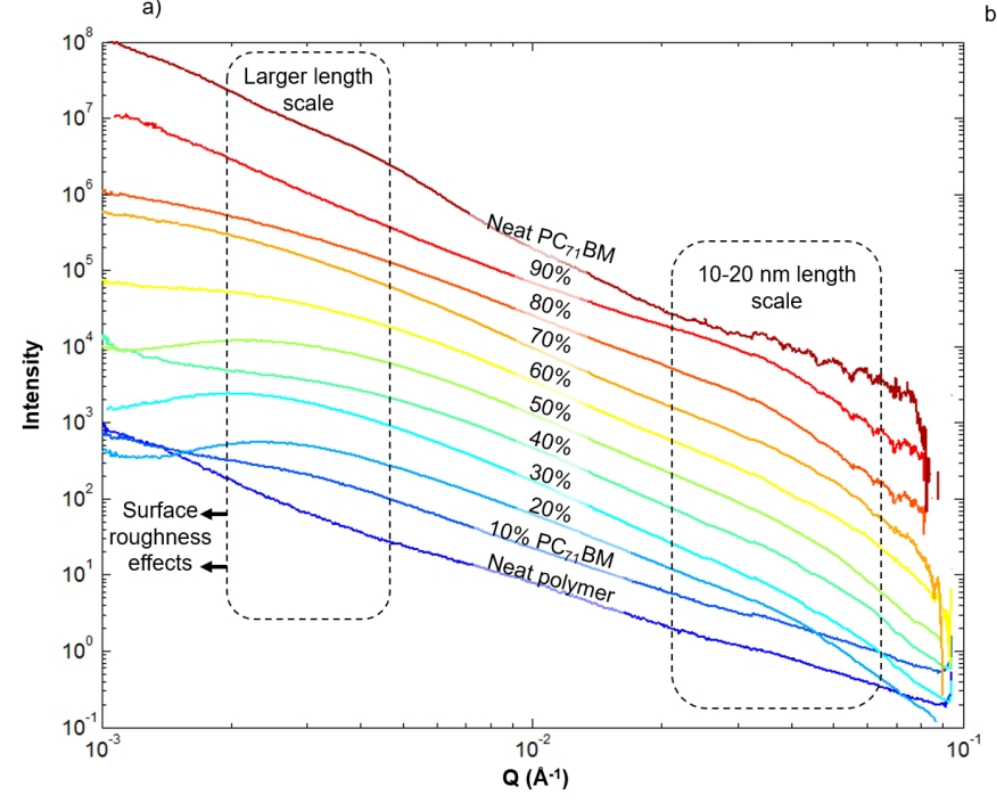

b)

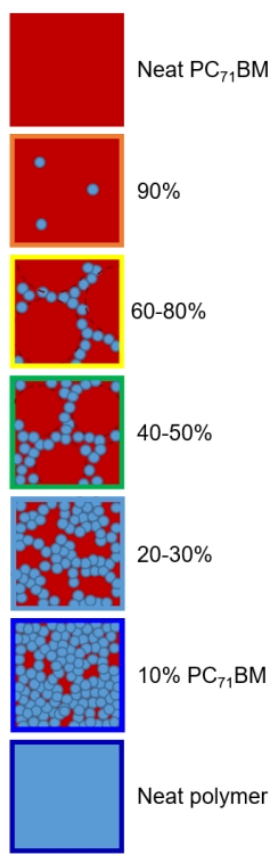

Figure 7. a) RSoXS results from a blend ratio series of PBDTTPD(2EH/C8):PC 71 BM films at $284.2 \mathrm{eV}$ shifted for ease of comparison. Curves normalized by incident beam intensity and thickness, and equivalent curves at $270 \mathrm{eV}$, are shown in Figure S6. b) Schematic illustration of the microstructure of solid films of

PBDTTPD(2EH/C8): $P C_{71}$ BM with varying blend concentrations. Light blue circles represent $5-10 \mathrm{~nm}$ selfassembled polymer crystallites and dark red represents the aggregated fullerene matrix which fills in regions in between polymer crystallites.

$271 \times 184 \mathrm{~mm}(150 \times 150 \mathrm{DPI})$ 


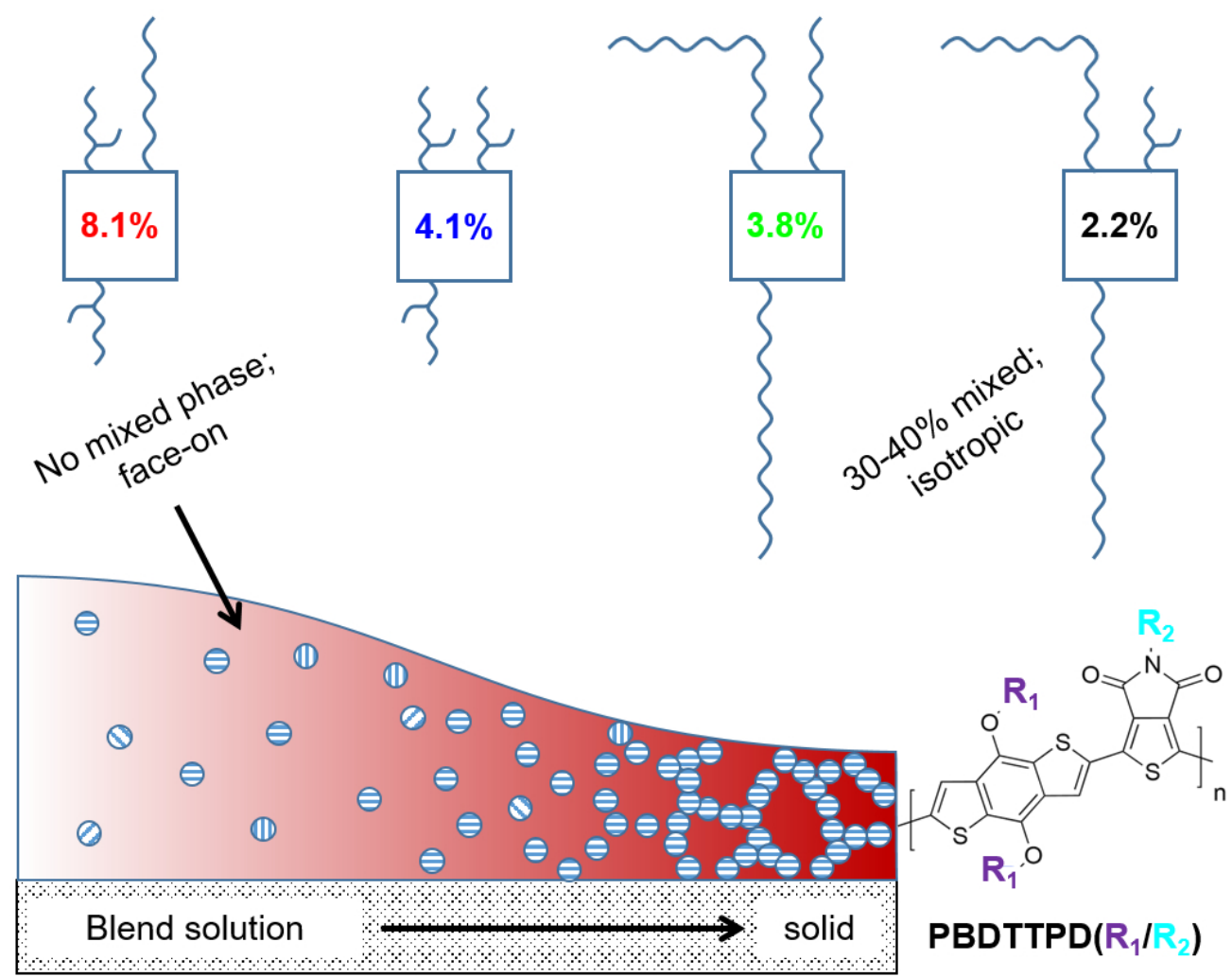

ToC figure

$174 \times 139 \mathrm{~mm}(150 \times 150 \mathrm{DPI})$ 